\title{
LA UNIDAD POPULAR: ENTRE LA ARMADA Y LA PARED*
}

\section{THE POPULAR UNITY: BETWEEN THE WALL AND THE NAVY}

\author{
Danny Gonzalo Monsálvez Araneda** \\ DANNYMONSALVEZ@UDEC.CL
}

\section{RESUMEN}

La mayoría de los estudios que se han desarrollado sobre el papel de los militares durante el gobierno de la Unidad Popular, se centran en describir y analizar el papel que jugó el Ejército y algunos de sus miembros, como el caso de los generales Carlos Prats y Augusto Pinochet, en la coyuntura 11 de septiembre de 1973; sin embargo, y a la luz de los antecedentes recopilados, es posible aseverar que fue la Armada, a través de José Toribio Merino y de otros almirantes, la institución más decidida a irrumpir e interrumpir el gobierno constitucional del Presidente Salvador Allende. En ese contexto, el siguiente trabajo examina las inquietudes y acciones desarrolladas e impulsadas por parte de algunos miembros de la Armada Nacional y de sectores opositores al gobierno del Presidente Salvador Allende entre los años 1970 y 1973.

Palabras claves: Armada, izquierda, Unidad Popular, marxismo, conjura.

\begin{abstract}
The majority of the studies on the role of the military during the Popular Unity Government have concentrated on describing and analysing the role of the Army and certain of its members such as generals Carlos Prats and Augusto Pinochet in the events that led up to the 11 th of September of 1973. Nevertheless, and in the light of the information gathered, it is possible to state that it was the Navy, through José Toribio Merino and other admirals, that was the institution most determined to interrupt and overthrow the constitutional government of President Salvador Allende. In this context, the following work analyses the concerns and actions carried out by certain members of the Navy and certain sectors in opposition to the government of President Salvador Allende between the years 1970 and 1973 .
\end{abstract}

Keywords: Navy, left, Popular Unity, marxism, conspiracy.

Hoy vence plazo de la Armada a Allende. Vicealmirante Merino lo notificó: Marinos somos antimarxistas por constitución... (Titular del Diario Tribuna, viernes 7 de septiembre de 1973)

\section{INTRODUCCION}

A más de 30 años del Golpe de Estado del 11 de septiembre de 1973 y a la luz del sinnúmero de información que ha ido apareciendo en torno a aquel proceso histórico, es un hecho innegable el descontento de algunos sectores como empresarios, gremios, partidos políticos y militares ante el triunfo de la Unidad Popular. En ese sentido podemos situar algunas acciones impulsadas por altos oficiales navales que desde antes del 4 de septiembre de 1970 vieron con inquietud y preocupación la llegada al poder de la izquierda marxista. Allí destacaban de sobremanera las actuaciones y comentarios de José Toribio Merino, Patricio Carvajal, Ismael Huerta y Sergio Huidobro Justiniano.

\footnotetext{
* Este trabajo forma parte del capítulo III de la Tesis de Magíster en Historia del suscrito intitulada "Agosto de 1973: La Inquietud Política en el Personal de la Armada: El caso de ASMAR Talcahuano".

**Profesor de Historia y Geografía y Magíster en Historia por la Universidad de Concepción. Docente de Historia de Chile Contemporánea en el Departamento de Ciencias Históricas y Sociales, Universidad de Concepción.
} 
Desde entonces algunos marinos entendieron que había que prepararse para enfrentar un sistema político distante de las costumbres y tradiciones chilenas. Sin embargo, ¿de qué manera o forma se podría canalizar el malestar o las críticas hacia el actuar de la Unidad Popular y de sus partidarios?

Como hipótesis central planteamos que desde el mismo momento de las elecciones de septiembre de 1970, la Armada, a través de algunos altos oficiales manifestaron su preocupación e inquietud por lo que sería un futuro gobierno de inspiración marxista, sustentado en una coalición socialista-comunista. Aquello implicó una clara actitud de contrariedad de sus altos mandos, situación que pasó de la disposición anímica hacia la organización y acciones contra el gobierno de la Unidad Popular. En otras palabras, preparar una intervención militar. Es en este escenario donde la Armada y especialmente algunos de sus altos mandos jugaron un papel preponderante, a contar de la crisis de octubre del año 1972 y de manera especial al constituirse el mes de julio de 1973 el grupo de los 15, donde por la institución naval estuvieron presentes Patricio Carvajal Prado, jefe del Estado Mayor de la Defensa Nacional y el contralmirante Ismael Huerta Díaz, hombres cercanos al almirante José Toribio Merino Castro y con funciones claves en la acción del 11 de septiembre.

Además, los preceptos de Seguridad Nacional adquirieron mucha fuerza en la institución, específicamente en lo referente a la preocupación constante por mantener la unidad y la seguridad nacional amenazada por un enemigo interno, situación que se ve reflejada a través de la Revista de Marina, como instancia de difusión del pensamiento institucional, a través de algunos artículos y opiniones sobre temáticas de seguridad nacional y análisis de problemas que afectan a la sociedad de la época.

La metodología empleada en este trabajo consistió en una primera parte en la compilación de información a través de bibliografías y fuentes referentes al tema. Acompañamos aquello con la identificación de algunos protagonistas directos de los hechos

Una vez compilada toda la información se procedió a ordenar aquella que nos fue de real utilidad, sobre la base de criterios estipulados al inicio del trabajo, finalmente y una vez ordenada la información de utilidad, se procedió a establecer los elementos de juicio, tanto diferenciadores como similitudes que nos conduzcan a certificar si nuestra hipótesis de trabajo estaba en la línea correcta o si correspondió realizar algún tipo de modificación de ella.

La bibliografía y fuentes utilizadas fueron algunos textos básicos sobre el periodo de la Unidad Popular, memorias y testimonios de algunos protagonistas, prensa y revista de la época.

\section{0: LA AMENAZA MARXISTA}

EL 4 de septiembre de 1970 los altos mandos institucionales, algunos de ellos reunidos en sus dependencias, específicamente en Valparaíso, veían con pavor cómo la actitud irresponsable de los partidos políticos había permitido el triunfo de Salvador Allende, poniendo en riesgo el futuro de la patria. El entonces director general de los Servicios de la Armada, almirante José Toribio Merino Castro, relata que pensó en retirarse de la institución pues "...no estaba dispuesto a servir a las órdenes de un Presidente que en nada representaba lo que para mí era más respetable y sagrado, como son el amor a Dios, a la Patria y a la Familia"'; sin embargo, el escenario cambió y finalmente optó por quedarse. ¿Qué motivó aquello? Eso lo veremos en las siguientes líneas.

Algunos, los más radicales pensaban que había que agotar todas las instancias en pos de evitar la llegada de Salvador Allende a la presidencia, actitud que tomó el entonces almirante Hugo Tirado Barros al involucrarse en el atentado que le costó la vida al general René Schneider ${ }^{2}$. Otros, recuerda Patricio Carvajal “...por lo menos, en la Armada y, según creo, en las otras dos instituciones también, era que el señor Allende debía terminar su periodo presidencial de seis años"”. Pero el dilema para un sector de la oficialidad era cómo afrontar en ese momento el nuevo escenario que se venía; entonces se deslizó la idea de ir a conversar con el candidato más votado, en este caso Salvador Allende, para saber cuál sería la política del nuevo gobierno con respecto a la Armada. Para el alto mando era un hecho que el Congreso Nacional ratificaría a Allende como Presidente de la República.

\footnotetext{
' Merino Castro, José Toribio. Bitácora de un almirante. Memorias. Santiago, Editorial Andrés Bello, 1999, p. 72.

${ }^{2}$ Al respecto véase: Monsálvez Araneda, Danny Gonzalo y Mario Eduardo Valdés Urrutia: "Recogiendo los pasos: Los movimientos deliberativos al interior de las filas del Ejército". Revista Notas Históricas y Geográficas, Universidad de Playa Ancha de Ciencias de la Educación, NoS 13-14, 2002-2003, pp. 191-214.

${ }^{3}$ Carvajal Prado, Patricio. Téngase Presente. Valparaíso, Imprenta y litografía Guerra, s/f, p. 156.
}

Revista de Historia, año 17, vol. 17(2), 2007, pp. 29-51 
La reunión entre Allende y los representantes de la Armada, encabezados por José Toribio Merino, jefe de los Servicios de la Armada y Raúl Montero Cornejo, comandante en jefe de la Escuadra, se efectuó el día 12 de septiembre de 1970. Según recuerda Merino, en la reunión estuvieron presentes, aparte de ellos tres, José Tohá, Luis Corvalán, Hugo Fazio, Luis Guastavino, Volodia Teitelboim, Jorge Insunza, Manuel Mandujano, Jorge Molina y Hugo Coloma ${ }^{4}$; sin embargo, el otro representante de la Armada y futuro comandante en jefe de la institución, Raúl Montero, niega rotundamente que en la cita haya habido más personas que Allende, Montero y Merino: "Yo no sufro de amnesia. Y las únicas personas que estábamos presentes éramos don Salvador Allende, al frente el almirante Merino y yo"s. Pero aquella discrepancia sobre la reunión con Allende aquel 12 de septiembre, será el inicio de las acciones de estos hombres, que estará marcada por las tensiones al interior de su institución. Mientras Montero se mantendrá contra viento y marea en la comandancia en jefe hasta el mismo 11 de septiembre, Merino será la pieza fundamental en la conjura contra el gobierno.

¿Pero por dónde pasaba la inquietud de la oficialidad ante el triunfo de la izquierda popular? ¿Por un simple estado de ánimo ante un escenario no previsto? ¿O por el temor a que su estructura disciplinada y jerárquica se viera alterada por los marxistas, una vez instalados éstos en el poder?

Como señaló Patricio Carvajal, en las Fuerzas Armadas hubo muchos que dijeron: "¿Vamos a tolerar nosotros que un marxista sea Presidente de Chile, sobre todo con una mayoría tan escasa como la que ha tenido?". El comandante en jefe de la Armada de aquel entonces Fernando Porta le manifestó que sí. Entonces, “...me encomendó a mí la ingrata tarea de recorrer las guarniciones navales -Santiago, Valparaíso y hasta Punta Arenas-, para conversar con los oficiales y decirles: "Esto es lo que ha querido el electorado chileno. No nos gusta; pero hay que aceptarlo asî".

O en último caso ser "....partidario de aceptar el régimen convencido de que en la elección de marzo de 1973 sería tan evidente el fracaso de la Unidad Popular que sufriría una gran derrota, y el Congreso - con clara mayoría opositora- sería capaz de obligar a Allende a enmendar rumbo o podría declarar su inhabilidad"'.

Dentro de la estructura institucional naval, el amor a Dios y a la Patria eran principios fundamentales en la formación de todo oficial de marina. En medio de toda la confusión y del golpe político que significó el triunfo de Allende, a comienzos de diciembre de 1970, Carvajal rememora en forma sacra su asistencia junto a otros militares a la procesión de la Virgen del Carmen, patrona de Chile. Allí se pudo contemplar "a los militares mezclados con los obispos, en un país que tenía un Presidente de la República marxista".

Ahora; "Todos, desde niños, hemos oído hablar de la patria. Le hemos entregado más de una vez nuestras emociones y hasta le hemos reservado un rinconcito en el joyero de nuestros afectos. Tal como a Dios que lo hemos imaginado o adorado en sus estampas, la hemos venerado e imaginado abstractamente en el emblema de nuestra bandera; y hasta hemos llegado a oírla a través del lenguaje de tambores, cornetas y timbales". En otras palabras, el concepto de patria para la Armada se constituía en "...un vínculo societario; es una tradición permanente, en la que no fenece el pasado, ni se detiene el presente, ni puede haber desentendimiento del futuro (...) un inmenso patrimonio moral, espiritual y material en el que está siempre presente el esfuerzo

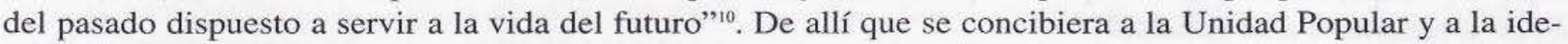
ología que llevaba inherente, como la amenaza latente de la destrucción de la sociedad y de las tradiciones nacionales.

En aquel contexto de bipolaridad mundial, los análisis y estudio de miembros de la institución sobre el peligro de la expansión rusa, el totalitarismo soviético y los rostros que adquiere el marxismo se hacían cada vez más recurrentes, especialmente el tema de una virtual invasión comunista en la región, específicamente en nuestro país.

Para Estados Unidos la idea de fortalecer y cooperar en la defensa de la región ante el peligro ruso los llevó a unificar ideológica y tácticamente a las Fuerzas Armadas de América. "Ello se tradujo en las firmas del Tratado Interamericano de Asistencia Recíproca, TIAR, en 1947 y el Programa de Ayuda Militar (PAM),

\footnotetext{
${ }_{5}^{4}$ Merino Castro, José Toribio. Opus cit., p. 78.

${ }^{5}$ González, Mónica. Chile La conjura, los mil y un días del golpe. Santiago, Ediciones B, 2000, pp. 39-40.

${ }^{6}$ Carvajal Prado, Patricio. Opus cit., p. 176.

"Almirante Patricio Carvajal, ministro de Defensa: "Las Fuerzas Armadas y...la Política": El Mercurio, domingo 22 de mayo de 1988 , p. D 1.

${ }^{3}$ Carvajal Prado, Patricio. Téngase Presente. Valparaíso, imprenta y litografía Guerra, s/f, p. 176.

${ }^{9}$ Dr. Alfonso Escribano V. "La Patria". Revista de Marina, enero-febrero de 1952, p. 71.

${ }^{10}$ Dr. Alfonso Escribano V. "La Patria", Opus. cit. pp. 72-73.
} 
que cada país firmó por separado. En el caso de Chile, éste fue suscrito en 1952. Ambos tratados comprometían la acción conjunta de las fuerzas militares chilenas con sus congéneres latinos y norteamericanos" ".

En pleno proceso de acuerdo entre nuestro país y los Estados Unidos por el Programa de Ayuda Militar, el vicealmirante en retiro Juan Rodríguez S. expresaba su preocupación por la falta de decisión de las autoridades políticas al dilatar dicho convenio. Rodríguez manifestaba que "ha pasado el tiempo y al presente existen otros problemas internacionales, pero se mantienen incólumes los principios de defensa de las naciones. En la actualidad, ante la situación del mundo, los pueblos se unen en una estrategia común, tanto en Europa como en América"12. La inquietud ante lo que estaba ocurriendo en Europa y el temor a que aquellas experiencias se trasladaran a América hacían imprescindible la ratificación de dichos acuerdos. Se necesitaban Fuerzas Armadas eficientes, preparadas para actuar en la defensa de la patria, "...recordemos que los éxitos de nuestro país en su vida independiente están íntimamente ligados a las armas de la nación. Son, pues, estas razones más que suficientes para que tengamos nuestras Fuerzas Armadas en el pie que corresponda a las tradiciones de nuestra patria"13.

Pero los análisis de los hombres de mar no se reducían solamente a la ayuda de los Estados Unidos; sino que también se hacían referencias a otros temas de contingencia hemisférica, como el de las guerrillas, seguridad nacional, expansión Rusa y el papel de las Fuerzas Armadas, del cuerpo de oficiales y de la misma institución naval.

Las experiencias guerrilleras asociadas a la izquierda “...han brotado en Sudamérica, algunas demasiado cerca de nosotros para despreocuparnos de ellas y que no son otra cosa que actos violentos destinados a forzar a los gobiernos a someterse a su voluntad"14.

La eficacia de las guerrillas había tenido su estallido desde fines de la Segunda Guerra Mundial; aquello no era un tema insignificante en el contexto de la Guerra Fría, así por lo menos lo entendían los militares "...la pequeña 'guerra' o 'guerrilla' es un tema al cual no se le puede dejar de dar importancia, y en esos institutos (estudios militares) se leen entre otras las obras de Mao y Che Guevara, maestros en el arte moderno de la convivencia pacífica que no sería más que la continuación de la guerra por otros medios"

El peligro que se veía en estas expresiones de guerra insurreccional, en la década de los sesenta, pronosticaba que las Fuerzas Armadas debían estar preparadas eficazmente para enfrentarlas. De acuerdo con el análisis desarrollado por el vicealmirante en retiro Balaresque: "Los objetivos de las guerrillas son: en primer lugar, tratar de desprestigiar al gobierno acarreando presión política extranjera y simpatía a favor de su causa y ocasionar su caída. En segundo lugar si no logran el triunfo o el apoyo foráneo, fomentan la guerra civil formando sus propias fuerzas militares insurgentes, capaces de enfrentar en combate a las tropas regulares..."

Finalmente dentro de la información se remarca que en el contexto de Guerra Fría, las guerrillas son una preocupación de la cual los gobiernos no se pueden desentender. De allí que todo gobierno que se califique de democrático debe prevenir, evitar y reprimir toda expresión de guerrilla o asociada a ésta; de lo contrario, una vez desatado aquél conllevará la muerte de muchas vidas, el prestigio y el tiempo de aplacarlas. Las guerrillas son "La continuación de la política por otros medios y constituyen actos violentos destinados a forzar al país a someterse a su voluntad"17.

El examen informativo que desarrollan miembros de la institución a través de la Revista de Marina, se abocó también al tema de la Seguridad Nacional, como un instrumento eficaz ante la amenaza latente del comunismo en los países de América del Sur.

Para el capitán de Corbeta Rubén Scheihing Navarro las atribuciones privativas del Estado definido como una "persona jurídica, encargada en el pueblo de un determinado territorio políticamente organizado de declarar y hacer respetar el derecho y de promover el mayor bien común, son bajo el punto de la Seguridad Nacional, la representación internacional de la Nación; la Defensa Exterior y la Seguridad Interior; las funciones de policía y la Administración de la Justicia"18. En otros conceptos, la Seguridad Nacional es una res-

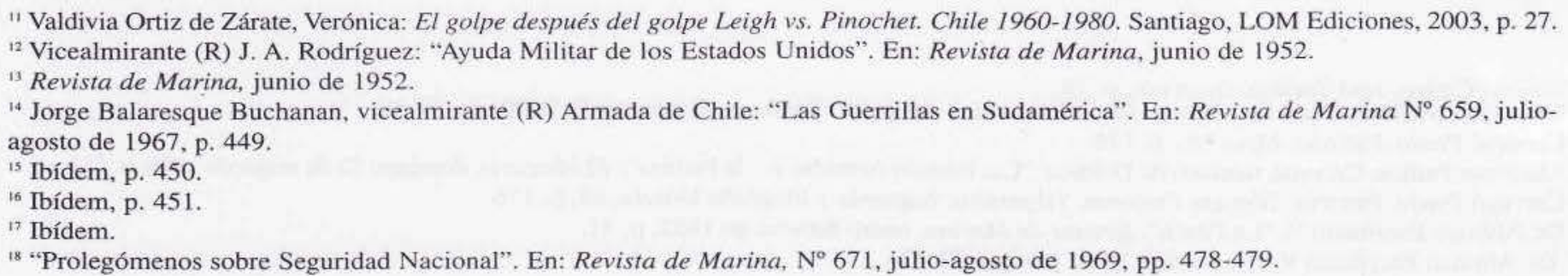

Revista de Historia, año 17, vol. 17(2), 2007, pp. 29-51 
ponsabilidad del Estado, no se relaciona exclusivamente con los aspectos militares e incumbe a todos los ciudadanos por igual.

Un punto importante dentro del estudio es la relación Seguridad Nacional y países subdesarrollados, para Scheihing: "Los países pobres o en vía de desarrollo, al no contar con los capitales para explotar sus recursos naturales, en el fondo están hipotecando su Soberanía, o lo que es lo mismo, condicionando su Seguridad Nacional..."' . En esa realidad se encontraría nuestro país y lo que es peor aún, apunta el analista, el peligro de improvisar y especular con fórmulas o experiencias foráneas que no se adaptan a nuestra realidad conllevan el riesgo de no adoptar políticas y planes de acción eficientes que tengan como objetivo el bien común; en otras palabras, afianzar el tema de la seguridad. "Si hay algo que la seguridad supone, es un mínimo de orden y estabilidad. Pero el subrayar que la seguridad dimana del desarrollo no niego que "una nación subdesarrollada pueda ser subvertida desde dentro o sufrir una agresión exterior o ser víctima de una combinación de ambas cosas"20.

El tema de la estabilidad institucional es tratado con especial cuidado, en ello la variable política juega un rol trascendental. La estabilidad general, confianza en el ciudadano, por ende permite el desarrollo de los países, en este caso el nuestro. ¿Qué papel desempeña la variable militar dentro de la óptica de Seguridad Nacional?, "...las FF.AA. deben prepararse física, material, intelectual y moralmente para contrarrestar o destruir, si fuese necesario, a todos los enemigos externos o internos, actuales o potenciales, que le amenacen" ${ }^{21}$.

Si bien los estudios desarrollados sobre seguridad nacional no se reducen exclusivamente a materias de defensa, sino también a los planes de desarrollo económico de cada nación, de allí su preocupación por las políticas implementadas por aquellos países en vías de desarrollo como Chile, al señalar que "no debemos caer en el error de pensar que con sólo nacionalizar nuestras riquezas básicas, un país puede logra su independencia económica". Ahora la preocupación reflejada por la presencia de un enemigo interno conlleva a resaltar de manera directa el rol que debían cumplir las Fuerzas Armadas, entendidas como la “...espina dorsal de la estructura del gobierno, sustentación fundamental e indispensable para mantener inalterable e inalienable las libertades democráticas"22.

Factor de preocupación dentro de los escritos que publica la Revista de Marina era resaltar el poderío que había adquirido la Unión Soviética, en materia militar y de injerencia ideológica en otras latitudes:

En el corto periodo de una veintena de años, Rusia ha logrado extender su influencia hasta las puertas de América e infiltrarse, no sólo en el S.E. de Asia y en la India, sino en el mundo árabe y en el Africa negra.

(...)

El pacto de Varsovia, que no es solamente un instrumento militar, sino que le sirve para dominar mejor a sus propios aliados, imponiéndoles el estacionamiento de las divisiones rusas sobre sus territorios y la participación de los satélites en las maniobras comunes, con el pretexto de asegurar así la "solidaridad socialista"23.

La progresiva preocupación de parte de los uniformados por los temas antes descritos, no obedecía simplemente a un análisis de la realidad de otros continentes, por el contrario, las experiencias de Cuba, los grupos guerrilleros de los vecinos Perú, Bolivia y Argentina y las manifestaciones en otros países de América, llevó a adaptar estrategias de defensa interna. En otras palabras, prepararse para un enfrentamiento de este tipo. En ese tema se puede apreciar una opinión generalizada dentro de quienes exponen sus puntos de vista a través de la revista de la institución. Ahora, ¿qué papel le corresponde a las Fuerzas Armadas, a la Armada y dentro de ésta de forma especial al cuerpo de almirantes?, son preguntas a las cuales se les da una clara respuesta.

Para el entonces capitán de Navío Ismael Huerta Díaz, en un estudio sobre "El papel de las Fuerzas Armadas en el mundo de hoy" resulta de sumo importante, más cuando en el presente el poderío militar de la Unión Soviética y el afianzamiento de partidos comunistas poderosos son manifestaciones del periodo de

\footnotetext{
${ }^{19}$ Ibídem, p. 481.

${ }^{20}$ Capitán de Corbeta Armada de Chile Rubén Scheihing N., "Hacia una conceptualización de la Seguridad Nacional". En Revista de Marina, $\mathrm{N}^{\circ} 679$, noviembre-diciembre de 1970 , p. 715.

${ }^{21}$ Ibídem.

${ }^{22}$ Ibídem, pp. 716-717.

23 "La tenaz expansión rusa hacia Occidente". En: Revista de Marina, № 676, mayo-junio de 1970, p. 301.

${ }^{24}$ Revista de Marina, № 665, junio-agosto de 1968, p. 484.
} 
postguerra. Lo anterior es acompañado por el subdesarrollo en el cual está inmersa América Latina, alcanzando niveles de crecimiento $(1,1 \%)$ muy escuálidos si se compara con los de los países desarrollados o industrializados $(4,5 \%$ y $8 \%)$, con un ingreso per cápita de 430 dólares, mientras que en Estados Unidos bordea los 3.000. Estos datos, según Huerta Díaz, nos indican que "estamos viviendo en breve plazo un proceso que otros países recorrieron en un periodo prolongado: integración nacional con incorporación de las masas a la ciudadanía, revolución social y, ahora, planes de integración regional. La situación resultante no puede ser sino de desorientación, incertidumbre y turbulencia" ${ }^{24}$. Pero al análisis pesimista que realiza Huerta, le adjunta el papel que deben librar las Fuerzas Armadas, especialmente sus miembros como ciudadanos preocupados y comprometidos con el desarrollo del país.

La postura de Chile se enmarca dentro de la integración latinoamericana, pero la integración sobre la base del descarte absoluto de la vía violenta como la lucha de guerrillas impulsada por Ernesto Che Guevara contra el imperialismo norteamericano y que finalmente fracasó producto que la población no respondió a los llamados de violencia, o por ser aplacada por la fuerza de los ejércitos regulares.

Será misión primordial de las Fuerzas Armadas abocarse a la defensa de la soberanía nacional, pero también recurrir cuando sea necesario al mantenimiento del orden institucional, actividades de bien público, ayuda en emergencias, todo en pro del desarrollo del país. Por lo tanto seguridad y desarrollo se complementan: "...no habrá desarrollo autónomo sin Fuerzas Armadas, ni tendremos fuerzas militares adecuadas sin desarrollo económico, social, cultural, científico y tecnológico"25. En tal caso el papel de las Fuerzas Armadas está en respaldar las acciones del gobierno que tengan como objetivo el desarrollo del país; porque las instituciones militares tienen como normas inmutables el cumplimiento del deber, honor, patria, soberanía, nacionalidad, disciplina y tradición. Entendido el patriotismo como el "....amor a la Patria en su más amplio sentido, en lo material y en lo inmaterial. Comprende, entre muchos otros aspectos, el amor al pueblo y a su bienestar, a la tradición y al ansia de progreso"26.

Enmarcado nuestro país en un conflicto mundial como es la disputa este-oeste, lleva a plantear las alternativas a las cuales se enfrenta el país en su camino hacia la integración para superar el subdesarrollo, asoma como una de las opciones a las cuales deberán enfrentarse las Fuerzas Armadas el levantamiento interno; esto quiere decir, actuar como fuerza de represión ante alzamientos intrínsecos. Será papel de las Fuerzas Armadas “...limitarse a proteger el orden o a dominar las transgresiones al mismo sin analizar sus objetivos, como toca a fuerzas no deliberantes y mientras se mantengan en este predicamento no podrán ser tachadas de agentes de coerción..." ${ }^{27}$.

Y dentro de aquel escenario, ¿cuál es la función de la Armada y la misión de sus oficiales? La respuesta puede ser amplia para la institución y puede ir desde la defensa costera, pasando por ser un instrumento de política exterior hasta un medio de llevar a cabo reformas sociales.

Para el cuerpo de oficiales, entendido "...como potencial humano insustituible, constituye la espina dorsal de la institución, en la que se apoya toda su estructura orgánica, material y espiritual..." ${ }^{28}$, su labor es vital en la tarea de servir al Estado en la tarea de defenderlo de los ataques externos e internos, y como cabeza directora de sus subordinados enmarcado en un disciplina estricta que se ve reflejada en el ejercicio del mando. De allí que "no se concibe, por supuesto, una sociedad sin disciplina, pues no habría forma de obtener un fin común sin una autoridad común"22.

Para la Armada y sus altos mandos las nociones de disciplina y espíritu son concepciones primordiales y suprainstitucionales. La vida espiritual en común “....aparece como de primerísima importancia, dentro de la misión del Cuerpo de Oficiales, la necesidad de revivir el Espíritu de Cuerpo, fuerza moral de enorme valor, que enaltece a cualquier institución que la posee y practica" ${ }^{30}$. Pero aquel espíritu de cuerpo requiere de la fe en la doctrina, en los hombres que la crearon y promulgaron y los encargados de aplicarla y regenerarla; todo aquello es lo que la Patria y la Armada nos exige con toda razón y derecho ${ }^{31}$.

\footnotetext{
${ }^{25}$ Ibídem, p. 490.

${ }^{26}$ Ibídem, p. 494.

${ }^{22}$ Ibídem.

${ }^{28}$ Ladislao D’Hainaut F., capitán de Fragata Armada de Chile, "Misión del Cuerpo de Oficiales". En: Revista de Marina, № 674, enerofebrero de 1970, p. 74

${ }^{29}$ Ibídem, p. 75.

${ }^{30}$ Ibídem, p. 77.

${ }^{31}$ M. Sánchez Alonso. "Más sobre la fe". En: Revista de Marina, №679, noviembre- diciembre de 1970, p. 793.
}

Revista de Historia, año 17, vol. 17(2), 2007, pp. 29-51 


\section{AL ABORDAJE DE LA UNIDAD POPULAR}

El segundo semestre de 1972, un grupo de civiles, específicamente algunos empresarios críticos del régimen, intercambiaban opiniones con algunos oficiales y ex oficiales de la Armada, analizando la delicada situación por la cual atravesaba el país. Pero aquellas conversaciones eran la continuación y profundización de viejos lazos de amistad que los mantenían unidos desde fines de la década del sesenta. Allí estaban el ex oficial de la Armada en retiro Hernán Cubillos Sallato, el director del diario El Mercurio Agustín Edwards, el ex oficial de la Armada Roberto Kelly y los almirantes Patricio Carvajal, Arturo Troncoso y José Toribio Merino. Todos ellos habían dado vida a la Cofradía Náutica del Pacífico. Al punto que cuando Agustín Edwards viajó a Estados Unidos, el almirante Merino fue designado comodoro de la Cofradía. ¿Cuál era el objetivo de aquella organización? Cubillos señala que "la cofradía nace como una inquietud que tenemos fundamentalmente Roberto Kelly, Agustín Edwards y yo de crear una especie de punto de encuentro de los civiles a los que nos interesaban las cosas del mar con los marinos profesionales" ${ }^{32}$. Aquella idea con el tiempo se transformó en uno de los puntos central de análisis político, pero principalmente de acciones a considerar ante la crisis por la cual atravesaba el país: "La evolución hacia los temas políticos fue un proceso natural, a medida en que se agravaba la crisis del país. De ese club fue naciendo una relación que nos permitió ir pasando información a

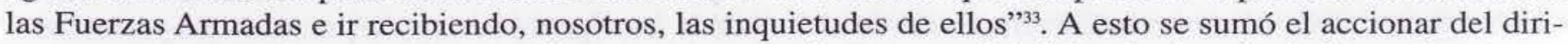
gente empresarial Orlando Sáenz, quien en un seminario empresarial del más alto nivel efectuado en septiembre de 1971 en el Hotel O’Higgins de Viña del Mar, y donde asistió entre otros Hernán Cubillos, en un análisis crudo de la realidad, manifestó que “...había llegado a la conclusión de que el gobierno de Allende era incompatible con la libertad de Chile y la existencia de la empresa privada. La única forma de evitar el fin era derrocarlo" ${ }^{34}$. La idea que en Chile se llegara a la dictadura del proletariado, o siguiera el modelo castrista, cundió en aquellos empresarios.

Si para Cubillos la Cofradía era una instancia de diálogo permanente sobre temas contingentes, especialmente políticos, el análisis de Sáenz de seguro les fue transmitido a los almirantes Merino, Carvajal y Troncoso y por supuesto a los altos ejecutivos de El Mercurio, quienes se transformarían en el medio de difusión más importante de los sectores disidentes al régimen.

El almirante José Toribio Merino, progresivamente se comenzaba a convertir en una de las piezas claves de la Armada, tanto al interior de la institución como en la tarea de estrechar vínculos con importantes y altos sectores empresariales, gremiales y políticos opositores a la Unidad Popular y que en gran parte compartían la inquietud y temor de la instauración de un régimen socialista en Chile.

Hernán Cubillos había tratado a Merino antes de la fundación de la Cofradía Náutica: "Lo conocí a través de mi padre, que también fue almirante y comandante en jefe de la Armada en los períodos finales de Jorge Alessandri, en 1964. En esa época, yo también era oficial de Marina. Me tocaba encontrarlo como superior y también en mi casa, como subordinado de mi padre. Los marinos jóvenes de esa época admirábamos su capacidad de mando y su espíritu audaz" ${ }^{\text {"35 }}$.

Para otro de los integrantes de la Cofradía, el empresario y amigo personal de Merino Roberto Kelly, éste (Merino) parece ser el más duro de los almirantes, pero eso se debía a que él "...era comandante en jefe de la Primera Zona Naval y recibía las quejas de las familias de la oficialidad que se encontraban en alta mar, y que tampoco las resuelve el almirante (Raúl) Montero"36.

Otro de los protagonistas del período, el Frente Nacionalista Patria y Libertad, había comenzado su propio combate contra la Unidad Popular. Los líderes de Patria y Libertad Pablo Rodríguez, Ernesto Miller, John Schaeffer y Roberto Thieme sabían que enfrentar a la Unidad Popular no era tarea fácil; por lo tanto una de sus estrategias sería ganar adhesión a su causa en el mundo militar. En el Manifiesto Nacionalista de noviembre de 1971, los "hombres arañas" señalaban: "Es también incuestionable que las FF.AA. no serán cómplices del comunismo en esta aventura totalitaria y que reaccionarán frente al caos, el desgobierno y la acción revo-

\footnotetext{
${ }^{32}$ Qué Pasa, 1 de septiembre de 1996, p. 5.

${ }^{33}$ Ibídem.

${ }^{34}$ González, Mónica. Opus cit., p. 119.

${ }^{3 s}$ Qué Pasa, 1 de septiembre de 1996, p. 5.

${ }^{36}$ Roberto Kelly: "Allende era un hábil político y un gran demagogo". La Segunda, serie de fascículos sobre Salvador Allende y la Unidad Popular, viernes 1 de agosto de $2003, N^{\circ} 1$, p. 13.
} 
lucionaria de sectores afiebrados y minoritarios. Es imposible que las Fuerzas Armadas y de Orden permanezcan al margen en tal evento. (...) y ante un pronunciamiento que evite la escalada revolucionaria del marxismo, institucionalmente desbordado, nuestro movimiento debe constituirse en respaldo cívico para un futuro gobierno militar nacionalista..." ${ }^{37}$.

La labor de examinar el terreno en el ámbito de las Fuerzas Armadas estuvo a cargo de John Schaeffer, quien al poco tiempo estableció nexos con un ex infante de Marina de nombre Vicente Gutiérrez, quien tenía la chapa de Javier Palacios, igual que el general del Ejército.

El primer gran momento de crisis que atravesó la Unidad Popular ocurrió como consecuencia del paro de transportistas de octubre de 1972; aquélla sería una coyuntura trascendental en el accionar de quienes consideraban que había que pasar decididamente a la ofensiva para detener el avance de la Unidad Popular y sus cuadros de izquierda.

Si bien Allende supo moverse bien ante el momento de trance institucional por el cual atravesó, recurriendo a la colaboración de los militares, específicamente del general Carlos Prats, para otros aquella movida estratégica significó derechamente el fin de la prescindencia de los militares. "Esto significaba que la presencia en el gabinete de las tres ramas de la Defensa Nacional aparecía respaldando políticamente la gestión gubernamental, lo que podía acarrear como consecuencia un quiebre institucional si, como señalaban los antecedentes de que disponíamos por filtraciones desde el área de la Inteligencia castrense, sectores mayoritarios de los uniformados definitivamente se habían expresado contrarios al régimen y a su ideología preponderante, el marxismo" 38 .

El gabinete cívico-militar contó, entre otros, con la presencia del contralmirante Ismael Huerta Díaz en la cartera de Obras Públicas y Transporte. Este, años mas tarde, comentaría en un seminario organizado por el Instituto de Ciencia Política de la Universidad de Chile en 1983, que se sintieron utilizados y fueron simplemente elementos decorativos del gobierno; es decir "...mostrar al Gobierno apoyado por las Fuerzas Armadas y usar a los militares para determinados fines" 39 .

La estrategia de paralizar el país y buscar el derrocamiento de Allende había fracasado; sin embargo, no todo fue negativo para los opositores a la Unidad Popular, la crisis de octubre obligó de ahí en adelante a Salvador Allende a ver a los militares como la única instancia viable para evitar el avance golpista de la oposición, lo cual obligó a las Fuerzas Armadas a transformarse en actores directos del conflicto entre el gobierno y la oposición.

Hasta esa fecha los sectores empresariales habían efectuado sus actividades opositoras de manera independiente, desarrollando acciones en busca de la desestabilización del gobierno, como por ejemplo el acaparamiento y mercado negro. A lo cual se agregó el llamado a la desobediencia civil, sumado al malestar progresivo por el excesivo intervencionismo del Estado en materia económica, ahogando a los privados. Así fue como confluyeron los gremios, el comercio y el transporte en el paro general de octubre de 1972, que buscaba la caída del gobierno.

Si bien Allende logró salir de la incómoda situación, los sectores gremiales y empresariales que habían impulsado y sostenido el paro de octubre de 1972, habían crecido de tal forma, que el escenario futuro se veía mucho más complejo para la Unidad Popular. Por otra parte estaba el papel que desarrollarían los empresarios, algunos de ellos como Hugo León, Orlando Sáenz y Julio Bazán que, reunidos a fines de diciembre de 1972 en el Hotel Carrera de Santiago, delinearon las ideas de realizar un gran paro nacional ${ }^{40}$. A esto se agregó la estrecha relación que habían establecido algunos empresarios y hombres de la Armada, la cual daba sus primeros frutos, sin antes tantear el terreno para una posible intervención militar. Así un grupo de civiles le planteó al almirante Merino la posibilidad, ante la grave crisis que se estaba viviendo, de que la Armada debería hacer algo, en clara alusión a una irrupción militar interrumpiendo la "vía chilena al socialismo"; a lo cual Merino respondió que aquello no era factible, principalmente porque a esas alturas, fines de 1972, no se contaba con ningún plan y programa a realizar de producirse el derrocamiento del gobierno. Sin embargo, producto de aquella coyuntura de los últimos meses del año 1972 va a surgir la idea de estructurar un plan económico que posteriormente sería conocido como el "Ladrillo"; base económica del gobierno militar.

\footnotetext{
${ }^{37}$ Fuentes W., Manuel. Memorias Secretas de Patria y Libertad. Y otras confesiones sobre la Guerra Fría en Chile. Santiago, Editorial Grijalbo, 1999, p. 100.

${ }^{38}$ Fuentes W., Manuel. Opus cit., pp. 159-160.

${ }^{39}$ Carvajal Prado, Patricio. Téngase Presente. Valparaíso, Imprenta y Litografía Guerra, s/f, p. 160.

4o "Programa Contacto" de Canal 13 de Televisión de la Universidad Católica de Chile, 2 de septiembre de 2003.
}

Revista de Historia, año 17, vol. 17(2), 2007, pp. 29-51 
Pero ya a comienzos de 1971, el economista Sergio Undurraga había empezó a realizar algunos estudios de corte económico para la Sociedad de Fomento Fabril. Paralelamente ejecutaban la misma tarea en El Mercurio, Sergio de Castro, Hernán Cubillos, Roberto Kelly y el abogado Carlos Urenda, vinculados fuertemente a grupos económicos.

Pero será Kelly quien canalice de mejor forma la idea de estructurar un plan económico. El ex capitán de navío pidió -entre otros- a Undurraga, De Castro y Emilio Sanfuentes que elaboraran un proyecto económico alternativo, con orientaciones claramente neoliberales aprendidas en la Universidad de Chicago.

Así algunos de los hombres que tuvieron participación en aquella medida fueron el ya citado Roberto Kelly, su amigo, el sociólogo Emilio Sanfuentes Vergara, vinculado al mundo empresarial, gremialista y cercano a algunos marinos y los economistas Sergio de Castro, Sergio Undurraga, Pablo Barahona y Alvaro Bardón. El objetivo fue facilitar el trabajo en materia económica a quienes sustituyan en el gobierno a Allende; en este caso a las Fuerzas Armadas.

Si bien la situación crítica por la cual atravesaba el país a comienzos del año 1973 se había tranquilizado con la incorporación de los militares en tareas de gobierno, la percepción al interior de la institución seguía siendo de una inquietud latente ante el problema de conducción política que estaba arrastrando al país a una crisis económica, social y moral. En su editorial, la Revista de Marina del año 1973 señalaba: "En medio de la grave crisis de valores morales que se advierte en las juventudes del mundo entero, es un síntoma halagador, que abre amplios y positivos horizontes de esperanza para el futuro de nuestra patria, el elevado número de jóvenes que este año postularon al ingreso en las escuelas de instrucción..."

"Este interés de nuestra juventud es una evidente demostración de que las nuevas generaciones ven en las

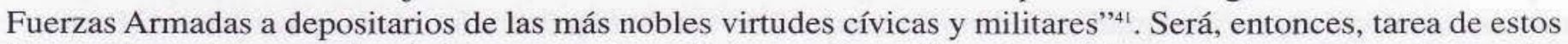
jóvenes honrados, alejados de las contiendas políticas, quienes "han de moldear sus almas y han de templar sus cuerpos para recibir de sus instructores y de sus jefes la tradición de respeto a los más puros y permanentes valores morales de nuestra patria; han de aprender a conservar y a acrecentar esta tradición; y han de hacerse dignos de ella, para que en un mundo agitado por las más exacerbadas pasiones, puedan convertirse en leales y celosos servidores de la patria"42.

El testimonio de Patricio Carvajal, recién nombrado en enero de 1973 jefe del Estado Mayor de la Defensa Nacional, es quien de mejor forma refleja aquellos días de alta temperatura: “...en ese tiempo, estuve en una reunión con el comandante Sergio Rillón (... ) el estaba muy deprimido. Al explicar el porqué de su estado de ánimo, decía que había estudiado con profundidad la Biblia, sobre todo el Antiguo Testamento, y había encontrado que la descripción de Satanás allí desarrollada cuadraba exactamente con la personalidad de Salvador Allende. En verdad, yo diría que el Presidente Allende poseía una habilidad diabólica para manejar a los hombres" ${ }^{\prime 43}$.

Pasado todo el período de agitación eleccionaria de marzo de 1973, éste no sólo dejó como conclusión que la Confederación Democrática no alcanzara los dos tercios en el Congreso para acusar constitucionalmente al Presidente de la República; sino que también delineo el nuevo rumbo de acciones que emprendieron los defensores y detractores del régimen. Para determinados almirantes, especialmente de la primera Zona Naval, donde Merino era la cabeza, la salida a la crisis cada vez más se veía por el lado militar. A esta idea se plegaban incondicionalmente Patria y Libertad, empresarios, gremios y sectores políticos de oposición, especialmente del Partido Nacional. Los contactos entre esto sectores se estrechan aún más. Había que preparar la ofensiva final, en otras palabras el desembarco de la Armada encabezada por Merino, Carvajal y Huerta.

Pasadas las elecciones se comenzaron a plasmar aquellas ideas esbozadas a fines de 1972 en el Hotel Carrera entre los empresarios León, Sáenz y Bazán, en el sentido de echar a andar la planificación definitiva para desestabilizar al gobierno; sólo había que buscar la fecha indicada para iniciar dicha acción. Se encomendó la tarea a siete ingenieros, quienes diseñarían el gran paro, el cual se desarrollaría en forma gradual hasta paralizar todo el país. "Nuestras fuerzas estaban radicadas en la posibilidad cierta de parar la energía eléctrica, el cobre, la CAP, los vuelos, Ferrocarriles, los hospitales"44.

En esa coyuntura se estrechan los vínculos entre oficiales de marina en servicio activo y empresarios que estaban diseñando la planificación del paro general. A los oficiales les interesaba de sobremanera saber cuál

\footnotetext{
41 "La Promoción Naval de 1973". En: Revista de Marina, № 692, enero-febrero de 1973, p. 1.

${ }^{42}$ Ibidem, p. 2.

${ }^{43}$ Carvajal Prado, Patricio. Opus cit., p. 179.

" Entrevista a Julio Bazán, presidente de la Cuproch en 1973: "Programa Contacto" de Canal 13 de Televisión de la Universidad Católica de Chile, 2 de septiembre de 2003.
} 
sería el apoyo con el cual podían contar si los militares se decidían a intervenir. Julio Bazán recuerda que "Los contactos no fueron iniciados por nosotros, se nos preguntó hasta dónde estábamos dispuestos a llegar"45. Mientras que Orlando Sáenz señala: "Los contactos míos a nivel de capitanes de navío y posteriormente con almirantes comenzaron por ahí por marzo, abril, fueron las primeras veces que yo tuve contactos personales. Ahí se planteaba que había que iniciar un montaje de un golpe de Estado, así de claro" "46. ¿Pero que unía a los empresarios con los oficiales de la Armada?, la inquietud y malestar por el aumento sin control de las tomas de fundos y fábricas, la creación de grupos armados, el desabastecimiento, el conflicto social, la disputa entre poderes del Estado, el peligro que Chile se convirtiera en un satélite de la Unión Soviética o en una segunda Cuba, crearon el clima de inseguridad institucional. La neutralidad de los militares, específicamente en la oficialidad naval, ya no era tal. Los almirantes, con Merino a la cabeza, tenían la sensación de estar ante autoridades ilegítimas e ilegales que estaba arrastrando al país a un descalabro político, económico, social y moral, escenario que los llevó a no permanecer inmutables ante el conflicto que se vivía día tras día. Situación que los condujo a estrechar vínculos con ciertos empresarios hasta poco antes del 11 de septiembre.

\section{LA UNIDAD POPULAR: ENTRE LA ARMADA Y LA PARED}

Uno de los momentos más álgidos y que sirvió para manifestar la postura crítica de algunos generales y almirantes con el gobierno, se suscitó cuando el ministro de Educación Jorge Tapia Valdés asistió el 11 de abril de 1973 a una reunión con 60 oficiales de las tres ramas de la Defensa Nacional para explicar los alcances del proyecto educacional del Gobierno (ENU). Allí algunos mandos hicieran público su rechazo al proyecto y la amenaza ideológica que éste significaba. Uno de los que hizo uso de la palabra fue el almirante Ismael Huerta, quien en duros términos manifestó su absoluta oposición al proyecto de la Escuela Nacional Unificada por considerarla un instrumento que busca la concientización de la juventud, imponiendo un régimen marxista concordante con el pensamiento ideológico del Presidente de la República. La Armada no estaba dispuesta a aceptar en sus cuarteles e instalaciones a jóvenes con un pensamiento ajeno a los principios fundamentales que propugna la institución.

Una vez terminada la intervención de Huerta, se escuchan estruendosos aplausos ${ }^{47}$. Huerta recuerda que "Todos, absolutamente todos los oficiales que opinaron en ese instante fueron contrarios a la ENU, en un tono bastante duro. Con esto se comprobó la unanimidad de pensamiento en la oficialidad de las tres instituciones de las Fuerzas Armadas" ${ }^{\text {"48 }}$. Esta fue seguramente la primera instancia donde los almirantes y generales anti Unidad Popular al unísono manifestaban abiertamente su discordancia con el gobierno.

Por otra parte, el almirante Merino narra en sus memorias a través de una serie de documentos navales, específicamente preparados por la Cámara de Almirantes en Retiro, la gravedad de la situación por la cual atravesaba el país. Allí se describen tanto las condiciones actuales del país, como los factores que han producido aquello. Se hace hincapié en los aspectos sociales y económicos, señalando como gran responsable de aquello al gobierno y a sus partidarios, quienes han azuzado una campaña de desprestigio constante contra el poder legislativo y judicial. Además, se ha promovido la institucionalización de organizaciones armadas y semimilitarizadas. Todo lo anterior a provocado entre otras cosas el éxodo de ciudadanos de alta capacidad técnica a países extranjeros y en contraposición la llegada a Chile de elementos extranjeros de dudosa reputación, que huyen de sus países por razones políticas y de extremismo, los cuales se caracterizan por su preparación técnica en guerrilla urbana y rural. A esto se agrega, la inmoralidad pública generalizada vista en la propaganda y en los medios de difusión ${ }^{49}$. Pero si bien se realizaba un riguroso análisis de la realidad nacional, aquello era acompañado de las posibles líneas de acciones o escenario que podían enfrentarse, insistiéndose en que de colaborar con el gobierno, ésta debe ser dentro de la absoluta doctrina institucional; fortalecer la unidad interna de la institución ante los ataques e intentos de división que pretenden algunos miembros de partidos políticos a través de la infiltración de sus mandos o personal. Como conclusión se manifiesta:

\footnotetext{
${ }^{45}$ Ibídem.

${ }^{46}$ Entrevista a Orlando Sáenz: Informe Especial, "Cuando Chile cambió de golpe”, Televisión Nacional de Chile, agosto de 2003.

${ }^{47}$ Prats González, Carlos. Memorias: Testimonio de un soldado. Santiago, Pehuén, 1987, p. 378.

${ }^{48}$ Disertación del vicealmirante Ismael Huerta Díaz en el seminario "Evolución Política de Chile 1964-1980", organizado por el Instituto de Ciencia Política de la Universidad de Chile, 1983. En: Carvajal Prado, Patricio. Opus cit., p. 168.

${ }^{49}$ Merino Castro, José Toribio. Bitácora de un almirante. Memorias. Santiago, Andrés Bello, 1999, pp. 178-180.
}

Revista de Historia, año 17, vol. 17(2), 2007, pp. 29-51 
1. Ante la grave situación que vive el país, el Alto Mando ha actuado en forma irresoluta y ha sido incapaz de tomar decisiones que hagan variar la política del gobierno.

2. Esta actitud pasiva ha creado un clima de frustración y desconcierto en toda la institución y en el país. Las razones se agotan, requerimos definiciones. Ha llegado el momento de actuar, pasemos de la actitud contemplativa a la ofensiva de la palabra y la acción. Defendamos la Patria en peligro. ¡Es una imposición histórica!

Por lo tanto pedimos

$1^{\circ}$. Una pronta definición del Mando que satisfaga nuestros ideales en base a oponerse a la dictadura marxista en todos sus frentes. Esta actitud tendrá el apoyo irrestricto de toda la oficialidad y personal a nuestro cargo. Esperamos confiados y serenos esta pronta definición.

$2^{\circ}$. En la medida que esto no se cumpla, tendremos un amplio diálogo con nuestros capitanes de Navío. Lleva contigo a los oficiales de tu buque o repartición. Se te indicará oportunamente lugar, fecha y hora ${ }^{50}$.

Hemos citado prácticamente en su totalidad el documento preparado por la Cámara de Almirantes en Retiro, por considerarlo de sumo interés en su contenido. Se observa en sus líneas una crítica directa al mando de la institución, en este caso al almirante Raúl Montero, por su manejo al frente de la institución. Su accionar ha contribuido a aumentar la inquietud del personal, especialmente entre los almirantes y a confundir la representatividad de la institución en tareas de gobierno. "La historia militar nos relata innumerables casos en los cuales la necesidad de una obediencia total y absoluta impidió toda crítica.

Entre los militares, esta preocupación por la imagen adquiere invariablemente las apariencias de una máscara de respetabilidad que, en muchos casos, los ha llevado a ocultar o distorsionar ciertos hechos para que faltas o incidentes graves queden en la obscuridad o sepultados para siempre" ${ }^{\text {"51 }}$. Los comentarios críticos sobre el accionar de Montero Cornejo, se habían generalizado. La Revista de Marina era un espacio propicio para que a través de diversos artículos o estudios tanto de personal chileno o adjuntando trabajos realizados por extranjeros se hiciera presente el malestar de la oficialidad. "Pero sigue siendo un hecho que la actitud del comandante se refleja en el subordinado. Si esta actitud es intolerante a la crítica, es fácil predecir cuál será la actitud que asumirán aquellos bajo él"52. La crítica solapada era acompañada por los constantes esfuerzos por resaltar los valores intrínsecos de la institución. Así, en medio de la crisis moral de la cual advierte la Armada está atravesando el país, el capitán Ladislao D'Hainaut F. expresa en un trabajo el valor trascendental de la "moral naval militar", entendida como el honor militar, el espíritu de cuerpo, subordinación, disciplina, entusiasmo, cumplimiento del deber, iniciativa, espíritu militar y cooperación. Aquello se complementa al manifestar que "siempre, y cada vez con más influencia, las fuerzas morales juegan un decisivo papel en la vida de los pueblos, tanto en la paz como en la guerra. De los dictados de esta ley natural nace, para cada uno de los miembros de la Armada, el deber de dar a este factor la importancia capital que merece"s3.

Retomando la declaración expuesta por la Cámara de Almirantes en Retiro, ésta nos deja algunas interrogantes, por ejemplo a qué se apunta cuando se señala que hay que pasar a la "ofensiva de la palabra y la acción" y que "el Mando satisfaga nuestros ideales en base a oponerse a la dictadura marxista en todos sus frentes". ¿Se está haciendo un llamado a la intervención militar?, ¿o se desea un cambio de mando al frente de la Armada? Seguramente de las dos cosas hay.

$\mathrm{Si}$ bien son almirantes en retiro quienes manifiestan esta dura sentencia, no es menos cierto que cuando un almirante o un general por muy en retiro que esté emite una señal de alerta, no solamente lo hace por él, sino que también lo hace por sus camaradas de armas en servicio activo. ¿Será que los ex almirantes son la voz de los sin voz?

Ismael Huerta nos da quizás la respuesta: "El error del Gobierno lo estimo grave, porque el Presidente Allende no entendió que los generales y almirantes tenían la misma escuela que los oficiales en servicio activo y, por lo tanto, la misma manera de pensar. De modo que, cuando les contestaba duramente a los generales y almirantes en retiro, les estaba hablando duramente a todas las Fuerzas Armadas en servicio activo"s4.

\footnotetext{
so Ibídem, p. 197.

${ }^{51}$ Teniente coronel P.M. Flammer. "La Crítica entre los Militares". En: Revista de Marina, Nº63, marzo-abril de 1973 , pp. 145-146.

${ }^{52}$ Ibídem, pp. 149-150.

${ }^{33}$ Revista de Marina, N 693, marzo-abril de 1973, p. 183.

${ }^{54}$ Disertación del vicealmirante Ismael Huerta Díaz en el seminario "Evolución Política de Chile 1964-1980" organizado por el Instituto de Ciencia Política de la Universidad de Chile, 1983. En: Carvajal Prado, Patricio. Opus cit., p. 170.
} 
Lo que sí es claro, es que así como la Unidad Popular había extraviado la ruta de navegación, en la Armada y en sus almirantes la carta de navegación ya estaba bastante definida y el próximo desembarque cada vez más cerca.

Paralelamente a los movimientos que realizaban algunos oficiales de la institución, el ex dirigente nacionalista Roberto Thieme y el Frente Nacionalista Patria y Libertad habían iniciado toda

...una campaña de sabotaje para cortar suministros de energía, viaductos, puentes, para paralizar el país y crear las condiciones objetivas de un golpe de Estado (...) yo mismo hablé con un comandante que era la mano derecha del almirante Merino que nos pide este trabajo y lo hacemos en conjunto. Estoy hablando de sabotaje, no de terrorismo ${ }^{55}$.

La radicalización ideológica, la institucionalización y legitimación de la violencia en la sociedad eran condiciones más que justificables para seguir adelante con la idea que la única solución efectiva a la crisis institucional era una intervención militar. Escenario altamente favorecido por la crisis económica, social y política por la cual atravesaba el país. Crisis que se circunscribía a la incapacidad de la política económica del gobierno y de los sectores productivos nacionales de responder a las demandas de la población, pero también producto del boicot económico y parlamentario de la derecha y del empresariado.

El mes de mayo es de sumo significativo para la Armada, allí se honra la memoria de Prat y sus compañeros, pero también y en vista del contexto que se vive, el acto del 21 de mayo tiene un simbolismo y una trascendencia especial. Así lo deja entrever un reportaje del diario El Mercurio en el día de las glorias de la Marina de Guerra. En sus líneas se señala la importancia valórica de la institución en la historia de Chile, deteniéndose en la participación de la Armada en los sucesos de 1891:

No obstante la Marina - por lo mismo que se identifica con la nacionalidad- no ha podido permanecer indiferente ante la ruptura de los moldes de vida ciudadana, ante el desintegrarse de sus instituciones, ante el quiebre de la Carta Fundamental, que constituyen una amenaza para la supervivencia de esa nacionalidad. Por ello creyó su deber intervenir en 1891, cuando el Presidente Balmaceda pasó por encima de la Constitución ${ }^{56}$. Y en clara alusión al Presidente José Manuel Balmaceda señaló que “...quiso marchar demasiado rápido y para esto infringió la Constitución y barrenó con ello los fundamentos del estado de derecho, que ha sido -desde Portales y quizás desde la Colonia-a la vez característica de la sociedad chilena y alimento de su progreso ${ }^{57}$.

El tenor de la cita posee palabras proféticas, pero no nos deja de extrañar que meses más tarde la Marina interviniera esgrimiendo los mismos argumentos que en 1891 y que Allende emulando a Balmaceda terminara con su vida y el de su gobierno disparándose un tiro. Entretanto, la Liga Marítima de Chile rendía también un homenaje a la Armada. En un almuerzo realizado en el Club Naval de Campo y donde asistió una delegación de altos jefes navales, encabezada por el almirante José Toribio Merino, Francisco Le Dantec hizo uso de la palabra y en un ensayo sobre el heroísmo expresó que

...el sentido del cumplimiento del deber deriva de un mandato moral establecido por la propia conciencia, como una forma de lograr el bien supremo, de alcanzar la virtud.

(...)

Por eso, el valor de un país no se mide por la cantidad de sus riquezas; no se calcula por el censo de su población; y tampoco se refleja en el tamaño o importancia de sus ciudadanos. El valor de un país se mide por la estatura moral de los hombres que producen. Cuando un pueblo tiene sentido heroico de la vida, forja su historia con caracteres de epopeya.

(...)

Nunca un héroe ha llegado a destiempo a su cita con el destino. Ni demasiado pronto, ni demasiado tarde. Siempre el heroísmo se ha manifestado en el momento en que era necesario ${ }^{58}$.

\footnotetext{
${ }^{35}$ Roberto Thieme: "Todos generamos un clima de odio y enfrentamiento". La Segunda, serie de fascículos sobre Salvador Allende y la Unidad Popular, jueves 14 de agosto de $2003, N^{\circ} 3$, p. 7.

${ }^{56}$ El Mercurio, lunes 21 de mayo de 1973, p. 1.

57 Ibídem.

${ }^{58}$ Revista de Marina, № 694, mayo-junio de 1973, pp. 321-322.
}

Revista de Historia, año 17, vol. 17(2), 2007, pp. 29-51 


\section{EL ASALTO FINAL}

Mientras algunos esperaban la coyuntura adecuada para actuar, otros almirantes como Carvajal y Huerta asistían a reuniones preparatorias en vista a la acción de las Fuerzas Armadas. A fines de junio de 1973 en casa de otro de los conjurados, el abogado Jorge Gamboa Correa en Lo Curro y con asistencia del general Gustavo Leigh, Arturo Viveros Avila, Francisco Herrera Latoja, Nicanor Díaz Estrada, Javier Palacios Ruhmann, Sergio Arellano Stark y Sergio Nuño, más los almirantes antes citados, uno de ellos, Ismael Huerta, con la anuencia y representación del almirante Merino ${ }^{59}$. Simultáneamente se daba origen a la estructura militar que tendría como objetivo la coordinación final del golpe de Estado, el grupo de los 15. Esta instancia nació como una iniciativa tendiente a debatir y estudiar líneas de acción ante los diversos problemas que afectan al país. Aquello surgió por invitación de Patricio Carvajal y Nicanor Díaz Estrada, a la fecha en la dirección del Estado Mayor de la Defensa Nacional, y sirvió para que aquéllos más comprometidos con una salida militar pudieran expresar directamente que ante el grosero escenario que vivía el país los militares no podrían seguir siendo meros espectadores. Aquella reunión a la cual "....asistieron los generales Pinochet, Sepúlveda, Bonilla, Nuño y Arellano, además de Prats. La Armada fue representada por su comandante en jefe, Raúl Montero; los vicealmirantes Merino y Carvajal; los contraalmirantes Ismael Huerta, Daniel Arellano y Ricardo León. La delegación de la Fuerza Aérea la encabezó el general Cesar Ruiz y la integraron los generales Leigh, Agustín Rodríguez, Claudio Sepúlveda, José Martínez, Nicanor Díaz y Francisco Herrera Latoja" ${ }^{\prime \prime 0}$, no fue sino el escenario propicio para que aquellos que de una u otra forma habían expresado su malestar con el gobierno aunaran fuerzas en pos de un solo objetivo: poner fin al gobierno de la Unidad Popular. Nicanor Díaz señala: "Con el pretexto de que estábamos estudiando los planes de guerra de la defensa nacional. Ese era el título oficial que le dimos a la figura, y lo que se le dijo a Prats" ${ }^{\text {" } 1 .}$

Así el grupo de los 15, bajo la venia de sus respectivos comandantes en jefes, se organizó de tal forma que no dio cabida a sospecha alguna sobre su accionar, que tuvo como línea de trabajo el inminente peligro en el cual se encontraba la Seguridad Nacional. La comisión de los 15 elaboró un informe confidencial, el cual se hizo entrega a los tres comandantes en jefes para que se hiciera llegar al Presidente de la República.

Este memorando confidencial hacía alusión al delicado momento institucional desde el punto de vista político, económico y social que vivía el país, lo cual directamente afectaba la Seguridad Nacional. En sus aspectos más sustanciales, el memorando elaborado por los 15 , se asemejaba bastante al elaborado por la Cámara de Almirantes en Retiro, del cual expusimos en líneas anteriores. Se hacía hincapié en el enfrentamiento del Poder Ejecutivo con los otros poderes del Estado, la politización del sector laboral, la indisciplina laboral, crisis de producción y la existencia de organizaciones y grupos armados paramilitares y extremistas que agravan la situación interna a través de actos de violencia claramente ilegales.

La amenaza y el peligro que conlleva la presencia de estos grupos no es un tema menor para la Armada. Si bien se prevé el peligro de que estos grupos posean armas, también se ve en ellos a agitadores ideológicos.

"La estrategia de la guerra ideológica, que es tan vieja como el mismo hombre, se basa en el simple principio de socavar, debilitar, dividir, azuzar y desmontar las reservas morales de la nación, de la sociedad y del individuo; y para ello, no repara en medios, todos son aceptables.

(...)

Es pues, el objetivo de la guerra ideológica no matar ni herir al cuerpo sino adueñarse del alma"62.

Las Fuerzas Armadas por cierto no están al margen de la guerra ideológica, aquéllos son flancos predilectos de quienes ostentan y desarrollan este tipo de acciones ".... a la tropa se le indispondrá contra sus jefes naturales, haciendo ver solamente sus defectos, magnificados hasta el límite (...) Así se hará llegar a los soldados a la conclusión de que están siendo utilizados por una pandilla de ignorantes, vagos y viciosos, para dominar a sus hermanos civiles"63.

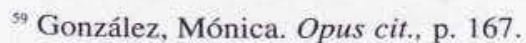

${ }^{60}$ Ibídem, p. 182.

${ }^{61}$ Marras, Sergio. Confesiones, Santiago, Ornitorrinco, 1990, p. 106.

${ }^{62}$ L.F. Bueno Rocero, teniente de Navío, Armada de España, "La Guerra Cotidiana". En: Revista de Marina, N 694, mayo-junio de 1973, pp. 287-288.

${ }^{63}$ Ibídem, pp. 289-290.
} 
Ante la amenaza que significa aquello es indispensable "...que nuestra mentalidad de oficiales debe adaptarse a los tiempos; la batalla que cotidianamente libramos y que es posible sea la única en que nos veamos envueltos, es una batalla ideológica, y si nos mantenemos alejados de ella, si ignoramos sus principios, carecemos de los conocimientos indispensables para vencer, y estaremos fatalmente condenados a ver, mudos e impotentes, cómo ante nuestra vista se deshace la patria que nosotros hemos jurado defender" ${ }^{4}$.

Pero a la preocupación por la presencia de grupos paramilitares, se suma la nula acción del gobierno en programas de desarrollo del área social, lo cual se ha traducido en un estado de agitación social que pone en peligro la unidad del país, factor primordial para la Seguridad Nacional.

Por último se realizó un llamado a adoptar medidas inmediatas como por ejemplo la aplicación irrestricta e indiscriminada de la Ley de Control de Armas, para terminar en forma definitiva con los grupos armados y paramilitares e ilegales y evitar que las Fuerzas Armadas o sus miembros sean aprovechados con fines políticos por sectores interesados que tratan de hacerlos aparecer políticamente comprometidos ${ }^{65}$.

Estas disposiciones eran un verdadero espolonazo al gobierno; en cada uno de los puntos que el memorándum señalaba, directamente se realizaban críticas a las medidas y acciones que hasta ese entonces había desarrollado la Unidad Popular. Más que un téngase presente del grupo de los 15 , era una verdadera advertencia a Allende. Los últimos puntos expresados, tanto el de la Ley de Control de Armas, como la no utilización de miembros de las Fuerzas Armadas en tareas de gobiernos con fines políticos partidistas, constituían lo puntos más delicados para el Presidente y los sectores de la izquierda chilena.

Pero no solamente el grupo de los 15 elaboró un plan de acción, en la Armada, concretamente en la Primera Zona Naval, el almirante Merino ordenó al jefe de Estado Mayor comandante Guillermo Aldoney y al jefe de Operaciones comandante Ramón Undurraga, la elaboración de un plan anti-insurgencia que señalara en qué sector de Valparaíso era factible que se suscitaran fuerzas paramilitares que significaran un peligro.

Aquel plan a mediados de julio estuvo listo y fue entregado a todos los mandos de la institución, siendo denominado como Plan Cochayuyo "...y se trataba de destruir o neutralizar todo foco de insurgencia que apareciere en la región, a fin de asegurar el normal desenvolvimiento de los servicios esenciales" ${ }^{66}$. Qué de particular o especial tuvo este plan de acción. Según Merino fue este plan el que se utilizó el 11 de septiembre.

Después del alzamiento del Blindado número 2 de Santiago a cargo de Roberto Souper, la tensión en el país aumento mucho más. Seguramente algunos ya esperaban el día D.

Si bien Patria y Libertad se encontraba en la clandestinidad producto de su fallido accionar el 29 de junio de 1973, aquello no significó que cesaran su accionar de agitación contra el gobierno, por el contrario, a mediados de julio el ex infante de marina Vicente Gutiérrez, quien entre otras cosas estaba a cargo de la formación de las brigadas operacionales de fuerzas especiales de Patria y Libertad, traía un mensaje de la Armada, el cual decía que necesitaban reunirse con Roberto Thieme y Miguel Sessa. La reunión a la cual asistieron Thieme, Sessa, un oficial naval y un capitán de marina se desarrolló en un departamento en Vitacura. Los marinos comunicaron "...que el 25 de ese mes de julio se iniciaría un nuevo paro nacional de los transportistas al mismo que, gradualmente, se sumarían otros gremios. Se buscaba paralizar completamente el país, generándose las condiciones para un pronunciamiento militar institucional" ${ }^{\circ 7}$. Pero ¿cuál sería el papel de Patria y Libertad en aquel escenario? Por petición de los representantes navales la idea era que miembros del Frente procedieran a cortar las vías ferroviarias, carreteras y oleoductos en los puntos que la Armada indicaría oportunamente; además, ellos facilitarían los explosivos. Pero estos representantes navales, ¿a quién representaban?, ¿eran simples hombres de mar que por iniciativa propia querían salvar la patria del marxismo?, ¿o eran dignatarios de personeros de mayor rango al interior de la institución?

Al respecto, Roberto Thieme ha declarado que él como dirigente del Frente de Operaciones de Patria y Libertad estaba a cargo de producir el sabotaje en la electricidad, caminos y combustibles, cortando flujos de cargas o mercancías a través de atentados contra ferrocarriles o puentes. Por ejemplo, rememora que pos Tanquetazo "...fui contactado por la Marina, por dos comandantes que trabajan con el almirante José Toribio Merino. En una reunión en Vitacura me dijeron (...) queremos informarle que a partir del 25 de julio se va a producir un nuevo paro del transporte. Nosotros vamos a apoyar ese paro y queremos que usted, con su gente,

\footnotetext{
${ }^{64}$ Ibídem, p. 290.

${ }^{65}$ Para una lectura y análisis más pormenorizado sobre este tema se recomienda ver: González, Mónica. Opus cit., pp. 501-507.

${ }^{66}$ Merino Castro, José Toribio. Opus cit., p. 207.

${ }^{67}$ Fuentes, Manuel. Opus cit., p. 296.
}

Revista de Historia, año 17, vol. 17(2), 2007, pp. 29-51 
nos den un apoyo logístico para paralizar el país (...) empezamos con la noche de las mangueras largas, que significó la falta de abastecimiento de casi todas las bombas de servicio. Después continuamos con los oleoductos ¿Alguien puede creer que nosotros sabíamos por donde venían los tubos desde Concepción a Santiago? ¡No, pues! Los marinos nos decían: en Curico, en el kilómetro tanto pasa el tubo (...) en definitiva Patria y Libertad puso la mano de obra y ellos la ingeniería y la logística" ${ }^{\text {" }}$. En consecuencia "...todas estas acciones eran dirigidas y organizadas por oficiales superiores de la Armada de Chile que estaban complotando contra Allende". Incluso -agrega Thieme- "comienza una presión a Patria y Libertad para que una vez cumplida la misión de sabotaje y crear las condiciones para un golpe, se empiece a atentar contra dirigentes de izquierda" ${ }^{\circ 9}$. Por ejemplo contra el secretario general del Partido Socialista Carlos Altamirano, situación a la cual él se opuso rotundamente.

Entretanto, la oposición civil-militar al gobierno seguía preparando la ofensiva final. Con motivo de los funerales del edecán naval del Presidente Allende, Arturo Araya P., algunos uniformados y civiles aprovecharon la ocasión para intercambiar opiniones en torno al difícil momento del acontecer nacional y las futuras acciones a seguir. Al respecto, el general de la Fuerza Aérea Nicanor Díaz Estrada, en una entrevista concedida a Sergio Marras, manifestó que "había un grupo de civiles que se reunía en la casa de Hugo León todos los lunes en la mañana, y que se habían juramentado para no descansar hasta botar a Allende. En ese grupo estaban Alfonso Márquez de la Plata, Orlando Sáenz, Julio Bazán, Manuel Valdés" "70. Informaciones que fueron complementadas al señalar "...que estuvo en reuniones para derrocar al régimen desde julio de 1973, reuniones que se efectuaban en la casa de un abogado, amigo del general Sergio Arellano Stark. En ella participaban por la Armada los almirantes Ismael Huerta y Patricio Carvajal" "' . Las reuniones prosiguieron los últimos días de agosto en la casa de Juan Kassis, dueño y fundador de las cecinas JK, en calle Pajaritos y en el Hotel Sheraton.

Pero sin duda quienes principalmente estaban moviendo los hilos de la conjura eran los ya citados hombres de la Armada, vinculados a la Cofradía Náutica del Pacífico, Hernán Cubillos S., ex oficial naval y a esa fecha empresario, más los almirantes Merino, Carvajal, Huerta, los capitanes de navío Hugo Castro, Arturo Troncoso, el ya citado Roberto Kelly Vásquez, y el ex infante de marina Vicente Gutiérrez relacionado con las brigadas operacionales de Patria y Libertad; a lo cual se agregaban los civiles Hugo León Puelma presidente de la Cámara Chilena de la Construcción, Julio Bazán presidente de la Confederación Unica de Profesionales de Chile (Cuproch) y Orlando Sáenz. Este último presidente de la Sociedad de Fomento Fabril (Sofofa), quien planeó una estrategia de tres puntos a seguir: activar un servicio de Inteligencia, conseguir apoyo financiero en el exterior y formar un equipo económico. Con respecto al servicio de inteligencia, Sáenz recuerda que "de inteligencia deben saber los detectives y los jefes de inteligencia de las FF.AA. Empecé a averiguar y Pablo Rodríguez me dijo: Conozco un coronel que acaban de echar del ejército por un problema de cheques sin fondos (...) una semana después estábamos conversando con él y el tipo dijo que era capaz de estructurar un servicio de inteligencia siempre que le dieran recursos"72. De esta manera Sáenz y su grupo de asesores recibían a tempranas horas de la mañana una valiosa documentación e información sobre las actividades de diversos personeros del Gobierno de la Unidad Popular.

Sobre los recursos que financiaban las actividades de la Sofofa, éstos eran obtenidos de empresarios nacionales como extranjeros, los cuales el mismo Sáenz se encargaba de gestionar:

Yo mismo hice contactos con sectores empresariales de otros países, a los cuales les debo lealtad y gratitud (...) En Europa, por ejemplo, trabajó un comité nuestro de tres personas (...) Pero, además, cada gremio llegaba con sus fondos. Le podría dar una nutrida lista de prohombres chilenos que hoy se expresan públicamente y que no tuvieron ningún empacho en recibir subsidios importantísimos para sus obras. ¿Sabe usted cuánto costó la campaña para salvar la Papelera, por ejemplo? Fueron cantidades enormes de dinero. Y sobre la base de allegar recursos, lo primero era tener medios de difusión. Teníamos una nómina de subsidios para treinta y tantas radios y más de veinte diarios a lo largo del país. Inventábamos publicidad. Era un ejército y toda esa actividad era necesaria. Nada más que la Sección Inteligencia nues-

\footnotetext{
${ }^{68}$ El Mercurio, martes 2 de septiembre de 2003, p. C 4.

${ }^{69}$ Declaraciones del ex dirigente del Frente Nacionalista Patria y Libertad Roberto Thieme al programa Informe Especial: "Cuando Chile cambió de Golpe" de Televisión Nacional de Chile, martes 12 de agosto de 2003.

${ }^{70}$ Marras, Sergio. Confesiones. Santiago, Ediciones del Ornitorrinco, 1990, p. 106.

"Revista Análisis, del 29 de agosto al 4 de septiembre de 1988, p. 36.

${ }^{72}$ Cita con la Historia: Orlando Sáenz ex presidente de la Sociedad de Fomento Fabril (Sofofa): "El paro del "72 derrocó a Allende". El Mercurio, domingo 29 de septiembre de 2002, p. D 19.
} 
tra llegó a tener casi 70 personas. Y todos esos grupos funcionaban en un lugar que no tuviera relación con las organizaciones empresariales ${ }^{73}$.

Finalmente, los informes que emitía el equipo encargado de la planificación y análisis económico de la situación del país, Sáenz los comenzó a hacer llegar a oficiales de la Marina desde fines de 1972.

A mediados de agosto las huelgas, paros, desabastecimiento, discrepancias entre poderes del Estado, rencillas internas en la coalición gobernante, abierta discusión en las filas de los institutos armados tenían en jaque a Salvador Allende. La formación, los primeros días de agosto de 1973, del gabinete de Seguridad Nacional había fracasado y dos de los comandantes en jefe habían renunciado a sus respectivas instituciones. En la FACH, César Ruiz Danyau, en una abierta discrepancia con Allende, dejó la Comandancia en Jefe en manos de otro de los conjurados Gustavo Leigh Guzmán. En una entrevista que le realizó la revista Qué Pasa y publicada el 30 de agosto de 1973, Leigh expresó ser partidario acérrimo de la libertad de expresión, de pensamiento, de espíritu y ante la consulta de si las Fuerzas Armadas pensaban dar un Golpe de Estado, respondió que él no contestaba insolencias ni groserías ${ }^{74}$.

Gustavo Leigh reafirma lo señalado por Díaz Estrada en líneas anteriores, en el sentido que era la Armada la institución que estaba más adelantada en los preparativos del golpe.

En la marina estaban mucho más adelantados. Cuando fueron los funerales del edecán Araya, a fines de julio de 1973, y yo fui a Valparaíso en representación de la Fuerza Aérea, se me acercaron unos capitanes de navío y me invitaron a almorzar.

(...)

Ahí se hablaba de frente de golpe. Estaban Walbaum, Castro, Troncoso y aparecieron dos civiles, Hugo Castro y Julio Bazán (...) Ahí me entregaron un folleto de programa económico que tenían proyectado; lo habían hecho unos economistas, era un programa económico. Parece que ya había contactos entre De Castro y esta gente, pero no tuve mayor conocimiento ${ }^{75}$.

Pero aún faltaba camino por recorrer. En una reunión efectuada a mediados de agosto entre el dirigente del Frente de Operaciones de Patria y Libertad Roberto Thieme y el ex infante de marina Vicente Gutiérrez se analizó los efectos que había tenido el paro y las acciones que se habían desarrollado en pos de producir la defenestración del Gobierno; se llegó a la conclusión “...que para entonces las condiciones objetivas para el derrocamiento del gobierno marxista estaban dadas. Ahora correspondía a las Fuerzas Armadas ponerle fin a la caótica situación interna y externa en que se encontraba Chile"76.

Con la decisión tomada por parte de Patria y Libertad, correspondía ahora informarse del ánimo a actuar al interior de las Fuerzas Armadas y específicamente en la Armada. Las informaciones eran coincidentes, la mayoría del generalato y de los almirantes en una actitud de cohesión y de decisión habían tomado la patriótica misión de poner fin a los casi ya mil días de la Unidad Popular. El sentimiento era uno solo, terminar cuanto antes con el caos y la destrucción producida por los marxistas.

A mediados de agosto las aguas al interior de la Armada, especialmente entre la alta oficialidad y su comandante en jefe, no eran las más tranquilas. El cuestionamiento a su autoridad y la pérdida de don de mando al interior de la institución eran evidentes, lo cual quedó de manifiesto en el Consejo Naval de mediados de agosto de 1973, al cual asistieron "...el vicealmirante Patricio Carvajal y los contraalmirantes Ismael Huerta, Daniel Arellano, Pablo Weber, Sergio Huidobro, Ricardo León, Hugo Cabezas, Adolfo Walbaum, Horacio Justiniano, Gerard Wood y Jorge Paredes, presididos por el vicealmirante Merino en reemplazo de Montero"' " En aquella cita, el contralmirante Justiniano manifestó que los almirantes creían que había una inconsecuencia entre lo resuelto por los generales y almirantes y la postura del comandante en jefe [Montero] de aceptar el cargo de ministro de Hacienda el 9 de agosto. Agregando que los oficiales habían perdido la confianza en el alto mando. Postura reafirmada por el almirante Walbaum y Huidobro al expresar que el país marchaba hacia el marxismo y que las Fuerzas Armadas amparaban la política de la Unidad Popular y que ante aquel escenario el alto mando no hacía nada por evitarlo. Si bien en aquella reunión no se hizo explícito hin-

\footnotetext{
${ }^{73}$ Entrevista de Mónica González a Orlando Sáenz, En: http://www.puntofinal.cl/010302/nactxt2.html

${ }^{74}$ Qué Pasa, No 124, 30 de agosto de 1973 , p. 39.

${ }^{75}$ Marras, Sergio. Opus cit., p. 130.

${ }^{76}$ Fuentes, Manuel. Opus cit., p. 306.

"Qué Pasa, 12 de septiembre de 2003, p. 36.
} 
capié en la renuncia de Montero, la posibilidad de una intervención militar fue un tema en el cual la mayoría de los almirantes coincidió. Las otras reuniones del Consejo Naval previa a la del 31 de agosto tuvieron el mismo tenor. Manifestar la inquietud del personal de la institución y del alto mando ante el accionar del comandante en jefe, principalmente al participar en un nuevo gabinete cívico-militar.

En uno de los últimos trabajos publicados por la Revista de Marina previo al golpe de Estado, se daba a conocer un extracto de una publicación del contralmirante de la Armada Donald Mac Intyre, intitulado "Lo que generalmente se olvida". En este trabajo se hacía hincapié en temas como la moral, la disciplina, la subordinación, el deber, el patriotismo y lealtad, entre otros. En sus pasajes principales se remarcaba el problema de un país que cuenta con hombres ineptos, irresponsables, flojos, indisciplinados y sin moral están condenados al fracaso. Que dentro del tema de la moral existen “...fuerzas destructoras que tratarán de envilecer al ciudadano y destruirle su moral: ellas son el egoísmo, la envidia, la venganza, el orgullo y la ambición desmedida" ${ }^{178}$. En contraposición a aquello hay que anteponer la verdad y la moral cristiana como aspectos trascendentales de amor al prójimo y servicio a la comunidad. A esto se suma el tema de la disciplina entendida como la esencia misma de la existencia de una nación, de allí que a los hombres les agrada ser mandados por jefes de cualidades superiores y con un carácter resolutivo y capaz. El artículo enumera otras actitudes que deben desarrollar los ciudadanos chilenos, pero especialmente la juventud chilena, quien tiene que meditar seriamente en el porvenir, porque de ellos depende el futuro de Chile.

Este trabajo, si bien se circunscribe a un ámbito académico, es una expresión clara de las inquietudes que rondan en el ambiente de los altos oficiales de la Armada. Los constantes análisis sobre el tema de la Seguridad Nacional, y los llamados a reforzar e inculcar la moral, el patriotismo y la fe se reiteran con mayor fuerza a medida que se acrecienta la ideologización política del país.

No cabía duda alguna que la mayoría de la oficialidad naval estaba decidida a actuar, pero hasta fines de agosto el obstáculo principal seguía siendo su comandante en jefe. Con un Montero desacreditado al interior de la institución, lo que había que hacer era forzarlo de alguna manera a presentar su renuncia. Instancia que ya había gestionado, al presentar en forma indeclinable su retiro de la institución los últimos días de agosto ante la reunión que efectuó el Consejo Naval y donde sintió que se había quedado sin el respaldo del cuerpo de almirantes; sin embargo, el Presidente Allende se la rechazó, argumentando entre otras cosas que los intereses de la institución y del país requieren de la permanencia de Raúl Montero al mando de la Armada de Chile.

¿Qué llevó a rechazar una vez más la renuncia de Montero? Seguramente el convencimiento de Allende que el nombramiento de Merino como comandante en jefe significaba reafirmar la postura de los almirantes que estaban por una salida militar a la compleja situación que vivía el país. En ese sentido Allende, apelando una vez más a su gestión política, decidió mantener contra viento y marea a Montero, como un dique de contención, dilatando la solución y el malestar del alto mando naval.

Pero la tarea de los almirantes de persuadir a su comandante en jefe en pos de insistir en la renuncia, le correspondió a Merino y Huidobro. Los primeros días de septiembre éstos se reunieron con su superior. Allí le manifestaron que la falta de mando que se apreciaba en su acción como comandante en jefe, y ante la presión que esto significaba y la tensión que estaba viviendo no le quedaría más que renunciar. No obstante, una vez más la renuncia se aplazó en una clara señal de divergencia entre Allende y los almirantes.

Según recuerda Merino en sus memorias, aquel día en el cual le solicitaron la renuncia a Montero se reunieron en horas de la noche con Allende. Allí estaban Huidobro, Merino, Montero y Cabezas. La conversación giro en torno a la conveniencia de producir un cambio de mando en la Armada, lo cual traería tranquilidad a los almirantes y al resto del personal de la institución, a lo cual el Presidente se manifestó en desacuerdo, esgrimiendo que el único en condiciones de pedir la renuncia de un comandante en jefe era él. Finalmente - evoca Merino- la conversación tuvo un tono desafiante que expresaba el ánimo entre la Unidad Popular y la mayoría de quienes al interior de la marina estaban en abierta oposición con el gobierno.

Entonces quiere decir que estoy en "guerra contra la Marina". Sí, señor, le contesté, estamos en guerra con usted. La Marina estará en guerra porque no es comunista y no será nunca comunista, ni los almirantes, ni el Consejo Naval, ni ningún marinero, pues estamos formados en otra escuela; la defenderemos hasta las últimas consecuencias, es nuestra vida y es la vida de nuestro Chile ${ }^{79}$.

\footnotetext{
78 "Lo que generalmente se olvida". En: Revista de Marina, N 695, julio-agosto de 1973, p. 415.

${ }^{79}$ Merino Castro, José Toribio. Opus cit., p. 218.
} 
Aquel fin de semana la situación llegó al máximo de tensión, cuando el sábado 1 de septiembre, reunido el Consejo Naval con presencia de los almirantes Patricio Carvajal, José Toribio Merino y los contralmirantes Ismael Huerta, Daniel Arellano, Pablo Weber, Sergio Huidobro, Ricardo León, Hugo Cabezas, Adolfo Walbaum, Horacio Justiniano, Gerard Wood, Jorge Paredes, Francisco Poblete, y del propio comandante en jefe y el ministro de Defensa Orlando Letelier, analizaron la difícil situación por la cual atravesaba el alto mando naval.

$\mathrm{Al}$ iniciar la reunión, el ministro Letelier expresó que el único con facultades para remover a un comandante en jefe era el Presidente Allende. Posteriormente, solicitó la opinión de cada uno de los presentes, exteriorizándose allí la postura de aquellos que abiertamente estaban por la salida de Montero. El primero en hacer uso de la palabra fue el almirante Merino, quien manifestó que lo único que deseba era que llegara el momento de su retiro y lo que menos deseaba era ser comandante en jefe de la Armada. A continuación expresó que “...el día anterior se había informado a Montero sobre la tensión interna, que se veía difícil de controlar y que podría traducirse en un sentimiento hostil hacía él (...) Agregó que la institución no deseaba ser marxista y que diferentes acontecimientos habían llevado a oficiales y personal a rechazar un sistema contrario a sus principios" ${ }^{80}$.

Posteriormente hablaron dos de los más cercanos a Merino, el almirante Patricio Carvajal, quien en una actitud de solidaridad con Merino, manifestó que si se da la instancia de que él tuviera que aceptar la comandancia en jefe de la institución, tendría un respaldo de todo el cuerpo de almirantes. Mientras que Ismael Huerta declaró que "...desde el 29 de junio se vivían situaciones difíciles en la Armada y que se había llegado al punto de tener que juzgar al propio comandante en jefe. Agrego que Montero no era factor de cohesión en la Armada y que Merino sí lo era""

Los almirantes que apoyaron a su comandante en jefe fueron Daniel Arellano, Hugo Cabezas, quienes incluso presentaron sus renuncias para dejar en libertad de acción a Montero, pero por sobre todo, fue Francisco Poblete, director de Abastecimiento y Contabilidad, el más directo de todos, éste en una verdadera catarsis le señalo a Letelier: "Mire, ministro, aquí lo que se está planteando es un acto de insurrección inaceptable. Usted tiene toda la razón en lo que ha dicho. Yo quiero hablar con usted delante de todos los almirantes, con la más absoluta franqueza. Dentro de la Armada se está alterando la disciplina, hay muchas personas alrededor de esta mesa que están en una actitud conspirativa" ${ }^{12}$. La defensa apasionada del almirante Poblete con Montero no fue otra cosa que denunciar ante el ministro Letelier la postura de la mayoría de los conjurados sentados alrededor de la mesa.

El último de los uniformados en hablar fue Raúl Montero, el cual en un tono moderado, como era su estilo, expresó que su actividad como comandante en jefe siempre había estado orientada en un claro sentido del cumplimiento del deber, que entendía la actitud emocional de los almirantes, pero que ante la compleja situación que se vive hubiese esperado el respaldo de sus pares.

Finalmente hizo uso de la palabra el ministro de Defensa, quien se comprometió a plantear lo conversado en la reunión al Presidente de la República. A los dos días después, el lunes 3 de septiembre, nuevamente se reúne el ministro con los almirantes para comunicarles que el Presidente Allende en pleno poder de sus facultades ha decidido rechazar las renuncias de los almirantes Daniel Arellano y Hugo Cabezas, siendo lo más importante, la decisión de mantener como comandante en jefe de la Armada a Raúl Montero Cornejo.

No cabía duda alguna que la casi totalidad de los almirantes deseaba la salida de Montero y la designación de Merino como nueva cabeza de la Armada; sin embargo, una vez más la estrategia no les resultó. Pese a aquel revés, la suerte de Montero y Allende estaba prácticamente sellada; días más tarde el propio Merino y Carvajal se encargarían de aquello.

El viernes 7 de septiembre se efectúa la reunión clave en la Oficina del Estado Mayor de la Defensa Nacional, entre quienes impulsan y conducen el movimiento militar que producirá la caída de Salvador Allende. Allí están José Toribio Merino, Patricio Carvajal y Sergio Arellano. En la cita, según recuerda Arellano, Merino relató su tensa entrevista con Allende aquel día viernes 7 de septiembre, en la cual se establecería el nombramiento de éste como nuevo comandante en jefe de la Armada, sin embargo, informaciones de prensa, específicamente del diario opositor Tribuna, al titular "Hoy vence plazo de la Armada a Allende", habían hecho desistir a Allende de nombrar aquel día a Merino, medida que fue postergada para el miércoles 12 del mismo mes.

${ }^{30}$ Que Pasa, 12 de septiembre de 2003, p. 38.

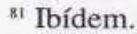

${ }^{82}$ Garcés, Joan. Orlando Letelier: Testimonio y vindicación. España, Siglo Veintiuno Editores, 1995, p. 38.

Revista de Historia, año 17, vol. 17(2), 2007, pp. 29-51 
Merino conmemora aquella tirante reunión con Allende:

Después de las 13:30 hrs. llegó el Presidente. Traía en la mano el diario y lo traía en alto y gritando como loco: "Para que usted vea, Almirante, le ha dado a la prensa noticias, informaciones, esto era absolutamente secreto, etc., etc., etc..."

Me levanté, me dirigí al Presidente que tenía en alto el diario, se lo quité violentamente y le dije: "Sépalo señor, que nosotros los marinos somos hombres de honor y el honor es sagrado, no se juega con el así no más, si alguien ha dado alguna información, ha sido su gente, a quienes no les importan estas cosas"; di media vuelta, y con el diario en la mano me dirigí hacia la puerta para retirarme, pero detrás de mí salieron el señor Letelier y el señor Allende que me cogieron de los hombros y me dijeron que no saliera; que conversáramos un rato. Yo traté de salir, pero no pude, no me dejaron ${ }^{83}$.

Pero más allá del tenor y de lo anecdótico que pudo tener la conversación con Allende que relata Merino, la reunión de los tres militares fue de carácter resolutiva. Se tomó la decisión de elegir el día de la acción, se barajaron algunas opciones como el fin de semana del sábado 8 , o domingo 9 de septiembre, para finalmente tomar la decisión de que

era indispensable decretar acuartelamiento en la noche previa con cualquier pretexto y para ello era obligatorio que el día anterior al " $D$ " fuera hábil, ya que los suboficiales se recogen a las 7 de la mañana y a esa hora ya habría sido tarde para comenzar. Por esta razón, y porque Carlos Altamirano y Oscar Guillermo Garretón deben comparecer ese día ante la Corte de Apelaciones de Valparaíso, lo que configura un excelente pretexto, se acordó el martes 11 de septiembre como el día "D" con hora "H" las 6 de la mañana para Valparaíso y las 8.30 para el resto del país" ${ }^{" 44}$.

Sergio Arellano a más de tres décadas de aquel hecho lo recuerda como si fuera hoy:

"El día 7 de septiembre me llamó por teléfono el almirante Merino, que estaba en Santiago, desde la oficina de Patricio Carvajal, que era jefe del Estado Mayor de la Defensa Nacional para que nos reuniéramos. Fui y me dijo que la Armada estaba muy inquieta, especialmente la Infantería de Marina, que había que tomar una decisión y que había almirantes que querían actuar el lunes 10. Llegamos a la conclusión de que era mejor el martes 11 porque era necesario acuartelar antes las tropas. Se acordó que fuera el martes 11 " 85 .

Después de aquella reunión, el almirante Merino se trasladó a Valparaíso, Primera Zona Naval, allí se reunió con almirantes y oficiales, en la Escuela de Artillería de las Salinas, para informarles de la reunión sostenida con Allende y de la negativa de éste a nombrarlo nuevo comandante en jefe de la institución. Agregó que no aceptaría aventuras militares de subalternos que intentaran arrastrar a la tropa en alguna acción y que él era el responsable del mando en Valparaíso, siendo su principal tarea mantener la disciplina institucional hasta las últimas consecuencias. Ese mismo día, en horas de la tarde, Merino redujo la reunión, esta vez en la Academia de Guerra Naval, solamente con almirantes, aquellos que se encontraban en el lugar y con quienes mantenía una mayor afinidad en cuanto a la acción que se desarrollaría el martes 11; en medio de la conversación llegó el almirante Patricio Carvajal, quien informó que la Fuerza Aérea estaba dispuesta a actuar, pero que la incógnita se mantenía en el Ejército, con su nuevo comandante en jefe, general Pinochet. Mientras tanto, la tarea de tantear el terreno aquel fin de semana con Augusto Pinochet la estaba desarrollando Arellano Stark. Este último no había podido concretar con Pinochet la acción del martes 11.

En vista de aquello, "Los almirantes que estábamos en ese momento en la Academia de Guerra teníamos que tomar la resolución: el Almirante (Ismael) Huerta, el Almirante (Adolfo) Walbaum, el Almirante (Ricardo) León, el Almirante (Sergio) Huidobro y el Almirante (Patricio) Carvajal, que nos dio la información. El Almirante Arellano se encontraba en Santiago como Ministro de Hacienda así como el Almirante Cabezas, jefe del Estado Mayor General de la Armada""

\footnotetext{
${ }^{83}$ Merino Castro, José Toribio. Opus cit., p. 224.

${ }^{84}$ González, Mónica. Opus cit., p. 281.

${ }^{85}$ El Mercurio, domingo 7 de septiembre de 2003. p. D 4.

${ }^{86}$ Merino Castro, José Toribio. Memorias. Opus cit., p. 226.
} 
La histórica y patriótica sentencia estaba tomada, faltaba solamente la coordinación final y el visto bueno de Pinochet y Leigh.

El domingo 9 de septiembre, en medio de toda la turbulenta situación que se vivía, los militantes y simpatizantes socialistas repletaron el Estadio Chile para escuchar las arengas de su secretario general Carlos Altamirano Orrego. Si bien Altamirano reconoce que aquel acto no aportaría en nada a buscar una solución a los problemas existentes, "pero que hubo un acuerdo general de la directiva del partido para que ese acto se realizara y para que yo fuera el principal orador"

En su discurso Altamirano hizo mención de su reunión con algunos marinos ${ }^{88}$, los cuales le manifestaron los planes golpistas de la oficialidad y que ellos estaban dispuestos a oponerse a un golpe de Estado; además, leyó una carta que enviaron los marineros y personal de la institución detenido acusados de sublevar a la Armada ${ }^{89}$. Quien tampoco se mantuvo impertérrito ante las palabras de Altamirano fue el almirante Merino, desde su casa en Valparaíso recuerda en forma sagrada como con lápiz y papel en mano redactó un mensaje al comandante en jefe del Ejército Augusto Pinochet y al comandante en jefe de la Fuerza Aérea Gustavo Leigh:

La patria nos exigía responder a nuestra razón de ser y existir.

Como he dicho, venía regresando de la Catedral y me puse a meditar sobre lo que significaría. En este país católico y mariano, vivir con un gobierno formado por un conjunto de marxistas ateos, sin ley, donde la moral cristiana desaparecería, donde todas las normas de la Ley de Dios y de los hombres se perderían en medio del materialismo corruptor. Pedí a Dios que me iluminara y a la Virgen que me diera una fecha $\mathrm{y}$, aunque no puedo asegurar que así fuese, el hecho es que puse como fecha el día 11 .

Tal como se desenvolvieron los acontecimientos, vistos con las perspectivas del tiempo, no puede negarse que fue un verdadero milagro de la Virgen del Carmen, Patrona y Reina de Chile... ${ }^{90}$.

Después de evocar la fe cristiana, Merino redactó el siguiente texto:

"9/Sept./73

"Gustavo y Augusto:

Bajo mi palabra de honor el día D será el 11 y la hora $\mathrm{H} 06.00$.

Si Uds. no pueden cumplir esta fase con el total de las fuerzas que mandan en Santiago, explícalo al reverso.

El Almte. Huidobro está autorizado para traer y discutir cualquier tema con Uds. Los saluda con esperanza de comprensión. J. T. Merino"

$\mathrm{Al}$ reverso agregué:

“Gustavo: Es la última oportunidad. J. T.

Augusto: Si no pones toda la fuerza de Santiago desde el primer momento, no viviremos para ver el futuro".

Pepe $^{91}$.

La tarea sería ahora del almirante Huidobro Justiniano, quien encomendado por Merino se dirigió a Santiago en busca de los respectivos comandantes en jefes de la Fuerza Aérea y del Ejército. Una vez llegado a Santiago se reunió con el jefe del Estado Mayor de la Defensa Nacional y pieza clave en el operativo de los últimos meses, Patricio Carvajal. Ambos se dirigieron a la casa de Pinochet, donde también se encontraba Leigh, a entregar el documento redactado por Merino y por cierto a esperar las respectivas confirmaciones. Las interpretaciones se entrecruzan, según algunos testimonios Leigh firmó de inmediato, mientras que Pinochet vaciló

${ }^{87}$ Cita con la historia: Carlos Altamirano: "La historia de Chile se ha hecho con duplas", El Mercurio, domingo 8 de septiembre de 2002 , p. D 23.

${ }^{88} \mathrm{Al}$ respecto véase nuestro trabajo: Monsálvez Araneda, Danny Gonzalo. "Agosto 1973: Proa al Golpe en la Armada: Los marineros antigolpe". Revista Tiempo y Espacio, Universidad del Bío-Bío, Facultad de Educación y Humanidades, Departamento de Ciencias Sociales, $\mathrm{N}^{\circ} 14,2004$, pp. 203 a 233.

${ }^{89}$ Sobre la carta de los marineros torturados a Salvador Allende véase: Farías, Víctor. La Izquierda Chilena (1969-1973) Documentos para el Estudio de su Línea Estratégica. Berlín, Centro de Estudios Públicos, volumen 6, p. 4.908.

${ }^{90}$ Merino Castro, José Toribio. Opus cit., p. 228.

${ }^{9}$ Ibídem, p. 229.

Revista de Historia, año 17, vol. 17(2), 2007, pp. 29-51 
un momento, hasta que persuadido por el jefe de la FACH finalmente firmó. Pero más allá del formalismo y de quién estampó su firma primero o segundo, o de si Pinochet mostró inseguridad o no, lo cierto es que aquel domingo 9 de septiembre se rubricó definitivamente el futuro inmediato de Salvador Allende y de la vía chilena al socialismo. Ahora sólo quedaba esperar el día D y la hora H; es decir, aquel martes 11 de septiembre de 1973.

Transcurrido el 11 de septiembre y con los militares instalados en el poder, las manifestaciones de satisfacción ante el nuevo escenario no se hicieron esperar. En su editorial, la Revista de Marina de septiembre y octubre de 1973, expresaba que "el nuevo régimen era esperado por la inmensa mayoría de la nación, pues el deterioro creciente de la moralidad, de la economía, de la seguridad y de la unidad de los chilenos era algo perceptible a simple vista". Mientras tanto, el vicealmirante en retiro de la Armada Juan Agustín Rodríguez, bajo el título "El Poder Militar Salvó a la Patria" señalaba "Estas fuerzas, oyendo el clamor de una mayoría ciudadana, se levantaron en armas el reciente 11 de Septiembre, no para dar un 'Golpe de Estado', sino para detener una 'Revolución Social' que amenazaba destruir la República'"92.

Más enfático fue en sus apreciaciones el nuevo comandante en jefe de la Armada y miembro de la Junta de Gobierno José Toribio Merino Castro, al expresar a través del órgano de difusión institucional:

"Quiero que sepan que lo que hago lo realizo por la Patria y por ustedes, por los chilenos todos y por esta Armada a la cual amo entrañablemente y por la cual daría mi vida si fuera necesario.

Quiero que ustedes amen a Chile y a su Marina por sobre todo después a Dios. Quiero que sirvan a su Patria (...) porque nosotros somos la Patria vigilante y entre todos la haremos grande y digna, noble y poderosa, respetada y respetable en todo el universo. Nosotros somos y seremos los responsables de su grandeza ciudadana"93.

\section{CONCLUSION}

La coyuntura eleccionaria de 1970 no sólo había expuesto las diversas ideas y divergencias de los partidos y fuerzas políticas del período; también sirvió para exteriorizar la correlación de fuerzas, y la temperatura ambiente que se vivió al interior de algunas reparticiones militares en vista a la elección del 4 de septiembre. En ese contexto, el triunfo de la Unidad Popular no fue visto por un sector de la oficialidad de la Armada como un fenómeno ajeno a sus intereses, o que los hiciera mantenerse impertérritos ante la llegada de un Presidente distante ideológicamente y de cómo veían la realidad los marinos. A ello se sumó la constatación por parte de los capitanes y oficiales que aquel 4 de septiembre un considerable número de personal de tropa y de baja graduación había expresado su alegría y satisfacción ante el triunfo de Allende.

En ese ambiente, desde un comienzo se constató una fuerte inquietud en un sector considerable de la oficialidad ante la llegada de un Presidente marxista al poder. Pero la opinión y la crítica privada en una primera instancia desde el cuadro de oficiales superiores de la Armada en contra del gobierno de Allende no era gratuita, o el reflejo de una simple y antojadiza disposición. Indudablemente, dentro del análisis que se puede hacer, había algunas variables decidoras, que con el transcurrir de los meses se fueron convirtiendo en profecías autocumplidas para aquellos altos oficiales que desde un primer momento manifestaron una abierta desconfianza y distancia con la Unidad Popular, situación manifiesta en las actitudes de algunos oficiales en su relación distante y tensa con la tropa.

En el análisis de la realidad que comenzaron a realizar determinados oficiales de la Armada, especialmente de la Primera Zona Naval, sobresalen algunos factores claves, por ejemplo, deslegitimación en la cual comenzaba a incurrir el gobierno: los conflictos de jurisdicción con otros poderes del Estado, el incumplimiento de algunos dictámenes provenientes de los Tribunales de Justicia, la vulneración de algunos principios como el de propiedad; además de los puramente ideológicos, fueron conformando un cuadro de deslegitimación del Ejecutivo, lo cual ponía -en opinión de la oficialidad-en serio riesgo la seguridad nacional. A esto se sumaba la progresiva invocación, entre los principales opositores al gobierno, de la condición marxista, atea y revolucionaria que explícitamente propiciaba Salvador Allende y la Unidad Popular.

${ }^{92}$ Revista de Marina, $\mathrm{N}^{\circ} 696$, septiembre-octubre de 1973, p. 557.

93 "Renacimiento de la Patria", En: Revista de Marina, N 697, noviembre-diciembre de 1973. p. 572. 
La solución para algunos uniformados, gremios y empresarios a la crisis ya no pasaba por el acuerdo político sino por la fuerza militar. Así fue como lo entendió la mayoría de la oficialidad naval, la cual buscó las instancias propicias para pedir la salida de uno de sus principales diques de contención, la de su comandante en jefe Raúl Montero Cornejo, atribuyéndole una falta y resolución de mando al frente de la institución; sin embargo, la estrategia de los oficiales de reemplazar a Montero por José Toribio Merino chocó una y otra vez con la negativa de Salvador Allende.

Finalmente, y ante la agudización de la crisis institucional por la cual atravesaba el país, la oficialidad naval, radicada preferentemente en la Primera Zona Naval, decide embarcarse en una aventura golpista tendiente a terminar con el Gobierno del Presidente Salvador Allende. Para la obtención de sus fines se impulsaron algunas acciones formales-institucionales canalizadas a través de su comandante en jefe como también por intermedio del Ministerio de Defensa; pero sin lugar a dudas, es un hecho innegable que se impulsaron acciones extrainstitucionales, de abierta intriga, conjura y sabotaje, tendientes a agudizar y acrecentar la inestabilidad del gobierno, con el objetivo final de crear las condiciones objetivas para llevar adelante un golpe de Estado institucional.

Finalmente, podemos decir que con el transcurso de los acontecimientos, de los años, y gracias a un importante número de entrevistas e informaciones publicadas en los diferentes medios, es un hecho de la causa que desde fines de 1972 y específicamente después de las elecciones parlamentarias de marzo de 1973, la Armada, a través de altos oficiales, venía preparando el terreno para una intervención militar. Situación que hemos querido demostrar a través de nuestra hipótesis de trabajo presentada en la introducción de este trabajo y que es respaldada por diversas fuentes que hemos citado debidamente y por informaciones que han ido apareciendo en los últimos años a través de diversos medios.

\section{BIBLIOGRAFIA Y FUENTES}

Carvajal Prado, Patricio e Ismael Huerta Díaz. 1983."El pronunciamiento militar de 1973: Fundamentos y antecedentes". Revista Política, № 4, Instituto de Ciencia Política de la Universidad de Chile. Edit. Universitaria, diciembre.

El Mercurio (Santiago), 4 de octubre de 1998; 6 de diciembre de 1998; 6 de agosto de 2000; 3 de junio de 2001; 8 de septiembre de 2002; 15 de septiembre de 2002; 22 de septiembre de 2002; 29 de septiembre de 2002; 6 de octubre de 2002; 3 de agosto de 2003; 6 de agosto de 2003; 10 de agosto de 2003; 24 de agosto de 2003; 31 de agosto de 2003; 7 de septiembre de 2003.

Farías, Víctor. La Izquierda Chilena (1969-1973). Documentos para el Estudio de su Línea Estratégica. Berlín, Centro de Estudios Públicos, 6 volúmenes.

Fuentes W., Manuel. 1999. Memorias secretas de Patria y Libertad. Y otras confesiones sobre la Guerra Fría en Chile. Santiago, Editorial Grijalbo.

Garcés, Joan. 1995. Orlando Letelier: Testimonio y vindicación. España, Siglo Veintiuno Editores.

González, Mónica. 2000. Chile. La Conjura, los mil y un días del golpe. Santiago, Ediciones B.

La Segunda (Santiago). Serie de Fascículos sobre Salvador Allende y la Unidad Popular, Desde el viernes 1 de agosto al viernes 5 de septiembre de 2003.

La Tercera (Santiago), 24 de marzo de 2002; 7 de abril de 2002.

Marras, Sergio. 1990. Confesiones, Santiago, Ornitorrinco.

Merino Castro, José Toribio. 1999. Bitácora de un Almirante. Memorias. Santiago, Editorial Andrés Bello.

Monsálvez Araneda, Danny Gonzalo 1999-2000. "Opiniones Políticas sobre el Rol de las Fuerzas Armadas en los gabinetes del Presidente Salvador Allende". Revista de Historia, Universidad de Concepción, años 9-10, pp. 123-149.

Monsálvez Araneda, Danny Gonzalo y Mario Valdés Urrutia. 2002-2003. "Recogiendo los pasos: Los Movimientos deliberativos al interior de las filas del Ejército". Revista Notas Históricas y Geográficas, Universidad de Playa Ancha de Ciencias de la Educación, Nos 13-14, pp. 191-214.

Prats González, Carlos. 1987. Memorias: Testimonio de un Soldado. Santiago, Pehuén.

Qué Pasa, 30 de agosto de 1973 y 12 de septiembre de 2003.

Revista Chile Hoy, № 54, 22 al 28 de junio de 1973, al № 65, 7 al 13 de septiembre de 1973.

Revista de Marina $\mathrm{N}^{\circ} 68$ de enero-febrero de 1952, al № 697 de noviembre-diciembre de 1973. 
Revista Punto Final. http://puntofinal.cl/

Revista Análisis, del 29 de agosto al 4 de septiembre de 1988.

Valdivia Ortiz de Zárate, Verónica. 1999-2000. "La historia que no fue: El proyecto social de los oficiales del Golpe”. Revista de Historia, Universidad de Concepción, años 9-10, Vols. 9-10, , pp. 151-188.

Valdivia Ortiz de Zárate, Verónica. 2003. El golpe después del golpe Leigh vs. Pinochet. Chile 1960-1980. Santiago, LOM Ediciones. 